\title{
$17 \beta$-Estradiol Acutely Potentiates Glutamatergic Synaptic Transmission in the Hippocampus through Distinct Mechanisms in Males and Females
}

\author{
기oseph G. Oberlander and Catherine S. Woolley \\ Department of Neurobiology, Northwestern University, Evanston, Illinois 60208
}

\begin{abstract}
Estradiol (E2) acutely potentiates glutamatergic synaptic transmission in the hippocampus of both male and female rats. Here, we investigated whether E2-induced synaptic potentiation occurs via presynaptic and/or postsynaptic mechanisms and which estrogen receptors (ERs) mediate E2's effects in each sex. Whole-cell voltage-clamp recordings of mEPSCs in CA1 pyramidal neurons showed that E2 increases both mEPSC frequency and amplitude within minutes, but often in different cells. This indicated that both presynaptic and postsynaptic mechanisms are involved, but that they occur largely at different synapses. Two-photon (2p) glutamate uncaging at individual dendritic spines showed that $\mathrm{E} 2$ increases the amplitude of uncaging-evoked EPSCs (2pEPSCs) and calcium transients (2pCaTs) at a subset of spines on a dendrite, demonstrating synapse specificity of E2's postsynaptic effects. All of these results were essentially the same in males and females. However, additional experiments using ER-selective agonists indicated sex differences in the mechanisms underlying E2-induced potentiation. In males, an ER $\beta$ agonist mimicked the postsynaptic effects of E2 to increase mEPSC, 2pEPSC, and $2 \mathrm{pCaT}$ amplitude, whereas in females, these effects were mimicked by an agonist of $\mathrm{G}$ protein-coupled ER-1. The presynaptic effect of $\mathrm{E} 2$, increased mEPSC frequency, was mimicked by an $\mathrm{ER} \alpha$ agonist in males, whereas in females, an ER $\beta$ agonist increased mEPSC frequency. Thus, E2 acutely potentiates glutamatergic synapses similarly in both sexes, but distinct ER subtypes mediate the presynaptic and postsynaptic aspects of potentiation in each sex. This indicates a latent sex difference in which different molecular mechanisms converge to the same functional endpoint in males versus females.
\end{abstract}

Key words: dendritic spines; estrogen receptor; sex difference; synapse

Significance Statement

Some sex differences in the brain may be latent differences, in which the same functional endpoint is achieved through distinct underlying mechanisms in males versus females. Here we report a latent sex difference in molecular regulation of excitatory synapses in the hippocampus. The steroid $17 \beta$-estradiol is known to acutely potentiate glutamatergic synaptic transmission in both sexes. We find that this occurs through a combination of increased presynaptic glutamate release probability and increased postsynaptic sensitivity to glutamate in both sexes, but that distinct estrogen receptor subtypes underlie each aspect of potentiation in each sex. These results indicate that therapeutics targeting a specific estrogen receptor subtype or its downstream signaling would likely affect synaptic transmission differently in the hippocampus of each sex.

\section{Introduction}

It has been known for decades that estrogens, such as $17 \beta$ estradiol (E2), potentiate excitatory synapses in the hippocampus

Received Dec. 12, 2015; revised Jan. 13, 2016; accepted Jan. 20, 2016.

Author contributions: J.G.0. and C.S.W. designed research; J.G.0. performed research;J.G.0. analyzed data;J.G.0. and C.S.W. wrote the paper.

The senior author is grateful to Anant Jain and Guangzhe Huang, members of her laboratory who performed and analyzed the mEPSC experiments reported in Figs. 1, 4,5, and 6 of the corrected article. Their extensive contributions to the study, which exceed the requirements for authorship, reflect their commitment to ensuring the accuracy of the scientific literature.

This work was supported by National Institute of Mental Health Grant R01 MH095248 to C.S.W.

The authors declare no competing financial interests.

Correspondence should be addressed to Dr. Catherine S. Woolley, Northwestern University, 2205 Tech Drive, Evanston, IL 60208. E-mail: cwoolley@northwestern.edu. within minutes, and in both sexes (Teyler et al., 1980; Wong and Moss, 1992). Although the physiological relevance of this effect initially was unclear, there is now compelling evidence that the hippocampus can synthesize estrogens as neurosteroids, which could provide a source of estrogens that fluctuate on the rapid time scale of E2-induced synaptic potentiation. For example, both the male and female hippocampus express the E2synthesizing enzyme, P450 aromatase (Roselli et al., 1985; MacLusky et al., 1994; Hojo et al., 2004; Tabatadze et al., 2014), and hippocampal cultures (Prange-Kiel et al., 2003), and acute slices (Hojo et al., 2004) produce E2 in vitro. These observations have 
motivated efforts to understand the cellular mechanism(s) that underlie acute E2-induced synaptic potentiation.

Results from separate studies provide conflicting evidence as to whether presynaptic versus postsynaptic changes underlie E2induced synaptic potentiation. Early experiments showed that E2 rapidly increases the amplitude of intracellularly recorded excitatory potentials evoked by glutamate application to CA1 pyramidal cells in slices (Wong and Moss, 1992) or after acute dissociation ( $\mathrm{Gu}$ and Moss, 1996), indicating that E2 increases postsynaptic sensitivity to glutamate (and/or sensitivity of extrasynaptic receptors). Subsequent studies supported a postsynaptic effect of E2. For example, Kramár et al. (2009) found that E2 potentiates extracellularly recorded dendritic field potentials in CA1 without affecting paired-pulse ratio. On the other hand, whole-cell voltage-clamp recordings in slices have shown that E2 potentiates EPSCs in CA1 pyramidal cells, at least in part, through a presynaptic mechanism. E2 potentiation of EPSCs occurred selectively at inputs with low initial glutamate release probability and was paralleled by decreased paired-pulse ratio, increased individual vesicle release probability, and greater cleft glutamate concentration (Smejkalova and Woolley, 2010).

One consistent finding, even among studies that have reached different conclusions about presynaptic versus postsynaptic mechanisms of E2-induced synaptic potentiation, is that estrogen receptor (ER) $\beta$ (ER $\beta$ ) plays an important role. The ER $\beta$ selective agonists WAY200070 (Kramár et al., 2009) and DPN (Smejkalova and Woolley, 2010) each were shown to mimic the effects of E2, whereas ER $\alpha$ agonists were not effective. Other studies, however, indicate involvement of ER $\alpha$ and G-protein coupled ER-1 (GPER1) (Lebesgue et al., 2010; Kumar et al., 2015). Thus, which ERs participate in E2-induced synaptic potentiation is unresolved. Another consistent finding in studies recording from individual neurons is that only a subset of cells (Wong and Moss, 1992) or inputs to cells (Smejkalova and Woolley, 2010) responds to $\mathrm{E} 2$, indicating that the effects of E2 at synapses are likely to be heterogeneous.

One complication in understanding the mechanism(s) by which E2 acutely potentiates synapses in the hippocampus is that most studies have been done in only one sex. For example, Kramár et al. (2009) studied exclusively males, whereas Smejkalova and Woolley (2010) and Kumar et al. (2015) studied exclusively females. To address this, we used whole-cell voltage-clamp recording and two-photon ( $2 \mathrm{p}$ ) glutamate uncaging in both sexes to: (1) investigate whether E2-induced synaptic potentiation occurs through presynaptic and/or postsynaptic mechanisms in males and/or in females; and (2) identify which ERs underlie E2-induced synaptic potentiation in each sex. The results show that $\mathrm{E} 2$ acts via both presynaptic and postsynaptic mechanisms in both sexes, but that each component of E2's actions is mediated by a different ER in each sex. Thus, the mechanisms of E2induced synaptic potentiation reflect latent sex differences in which the same endpoint is achieved through distinct mechanisms in males versus females.

\section{Materials and Methods}

Animals. All procedures were performed in accordance with the National Institutes of Health Guide for the Care and Use of Laboratory Animals and were approved by the Northwestern University Animal Care and Use Committee. Young adult male and female Sprague Dawley rats (Harlan) were group-housed on a 12:12 h light/dark cycle with phytoestrogen-free chow and water given ad libitum. Rats were either gonadally intact or gonadectomized. For gonadectomy, females were ovariectomized and males were castrated under ketamine $(85 \mathrm{mg} / \mathrm{kg}$, i.p., Bioniche Pharma) and xylazine (13 mg/kg, i.p., Lloyd Laboratories) anesthesia using standard aseptic procedures. Gonadectomized animals were used for experiments 5-8 d after surgery.

Electrophysiological recording. Rats were deeply anesthetized with sodium pentobarbital (100-125 mg/kg, i.p., Virbac) and transcardially perfused with oxygenated $\left(95 \% \mathrm{O}_{2} / 5 \% \mathrm{CO}_{2}\right)$ ice-cold sucrose aCSF containing the following (in mM): $75 \mathrm{NaCl}, 25 \mathrm{NaHCO}_{3}, 15$ dextrose, 75 sucrose, $1.25 \mathrm{NaH}_{2} \mathrm{PO}_{4}, 2 \mathrm{KCl}, 2.4 \mathrm{Na}$ pyruvate, 1.3 ascorbic acid, 0.5 $\mathrm{CaCl}_{2}, 3 \mathrm{MgCl}_{2}, \mathrm{pH}$ 7.4. Following dissection, $300 \mu \mathrm{m}$ transverse slices of the dorsal hippocampus were cut on a vibrating tissue slicer (VT1000S, Leica), incubated at $33^{\circ} \mathrm{C}$ in oxygenated regular aCSF containing the following (in mM): $126 \mathrm{NaCl}, 26 \mathrm{NaHCO}_{3}, 10$ dextrose, $1.25 \mathrm{NaH}_{2} \mathrm{PO}_{4}, 3$ $\mathrm{KCl}, 2 \mathrm{CaCl}_{2}, 1 \mathrm{MgCl}_{2}, \mathrm{pH} 7.4,310-315 \mathrm{mOsm}$, for 30-35 min, then allowed to recover at room temperature in oxygenated aCSF for $1-6 \mathrm{~h}$ before recording.

Slices were transferred to a recording chamber mounted to a Zeiss Axioskop equipped with a video camera (MTI NC-70 or Sensicam QE) and bathed in continuously oxygenated aCSF containing the following:

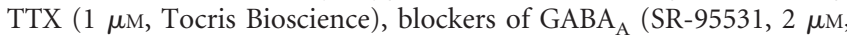
Tocris Bioscience), and $\mathrm{GABA}_{\mathrm{B}}$ (CGP46381, $10 \mu \mathrm{M}$, Tocris Bioscience) receptors and $0.01 \%(\mathrm{v} / \mathrm{v})$ DMSO (Sigma) at room temperature. In 2-photon experiments, the bath recirculated in a small volume $(\sim 10 \mathrm{ml})$ and also contained MNI-glutamate ( $1 \mathrm{mM}$, Tocris Bioscience). Wholecell voltage-clamp recordings $\left(\mathrm{V}_{\text {hold }}=-70 \mathrm{mV}\right)$ were made from CA1 pyramidal cells using borosilicate glass pipettes with resistances of 4-7 $\mathrm{M} \Omega$ containing the following (in $\mathrm{mm}$ ): $115 \mathrm{~K}$-gluconate, $20 \mathrm{KCl}, 10$ HEPES, $10 \mathrm{Na}$ creatine phosphate, $2 \mathrm{Mg}$-ATP, $0.3 \mathrm{Na}$-ATP, pH 7.3, 290-295 mOsm. In 2-photon experiments, the internal solution was supplemented with Oregon Green BAPTA 488 (OGB, $100 \mu \mathrm{M}$, Invitrogen) and Alexa-594 biocytin conjugate (100 $\mu \mathrm{M}$, Invitrogen) which were allowed to diffuse into the cell for $15 \mathrm{~min}$ after break-in. Recordings were acquired using an Axopatch 200B amplifier with pClamp 9.2 and digitized using a Digidata 1322A, or with a MultiClamp 700B amplifier with pClamp 10.4 and digitized using a Digidata 1440A. Recordings were filtered with a $2 \mathrm{kHz}$ low-pass filter, and digitized at $20 \mathrm{kHz}$. Series resistance $(10-40 \mathrm{M} \Omega)$ was monitored throughout each experiment with 5 $\mathrm{mV}, 10 \mathrm{~ms}$ voltage steps, and did not fluctuate by $>10 \%$ in recordings used for analysis. In separate experiments, miniature EPSCs (mEPSCs) or uncaging-evoked EPSCs (2pEPSCs, see below) were recorded for 10-20 min, which was followed by bath application of E2 (100 nM, Sigma), the ER $\beta$ agonist WAY200070 (WAY, $10 \mathrm{~nm}$, Tocris Bioscience), the ER $\alpha$ agonist PPT (100 nм, Tocris Bioscience), or the GPER1 agonist G1 (100 nM, Cayman Chemical), dissolved in 0.01\% (v/v) DMSO for 10 min. Thus, aCSF contained an equivalent concentration of DMSO in all phases of each experiment. In most recordings with ER-selective agonists, E2 alone was applied for an additional 10 min beginning 5-20 min after agonist washout to assess E2 responsiveness of each measured parameter.

$2 p$ glutamate uncaging at identified dendritic spines with simultaneous calcium imaging. Dendritic spines were visualized using a dual galvanometer-based $2 p$ laser scanning system (Ultima, Prairie Technologies) using a $40 \times$ objective with $16 \times$ digital zoom. Two ultrafast pulsed laser beams (Chameleon Ultra II, Coherent) were used: one split at 840 $\mathrm{nm}$ to image Alexa-594 and OGB, and one at $720 \mathrm{~nm}$ to uncage glutamate. Laser beam intensity was controlled with electro-optical modulators (Conoptics, model 350-50) with an uncaging dwell time of 0.5 or 1.0 $\mathrm{ms}$ at the minimum power required to evoke a 2pEPSC $(5-20 \mathrm{~mW}$, as measured at the back aperture of the microscope). Uncaging was focused at the edge of targeted spines. Each spine received an uncaging pulse once per minute with a $2 \mathrm{~s}$ interval between uncaging pulses at different spines.

Uncaging was performed at 1-6 spines per dendrite (one dendrite per cell), during which a line scan was taken over one spine and its parent dendrite with a pixel dwell time of $1.6 \mu$ s to record $2 p$-evoked calcium transients (2pCaTs). 2 pCaTs were measured as a 5 pixel average in the spine head and smoothed with a 9 point running filter after the uncaging flash was subtracted. $2 \mathrm{pCaT}$ amplitude was calculated as the change in ratio of OGB to Alexa-594 fluorescence during $300 \mathrm{~ms}$ following uncaging relative to the $50 \mathrm{~ms}$ average before the uncaging pulse. After record- 
A

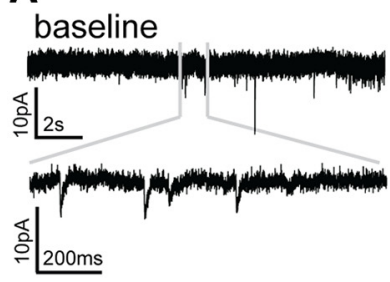

B
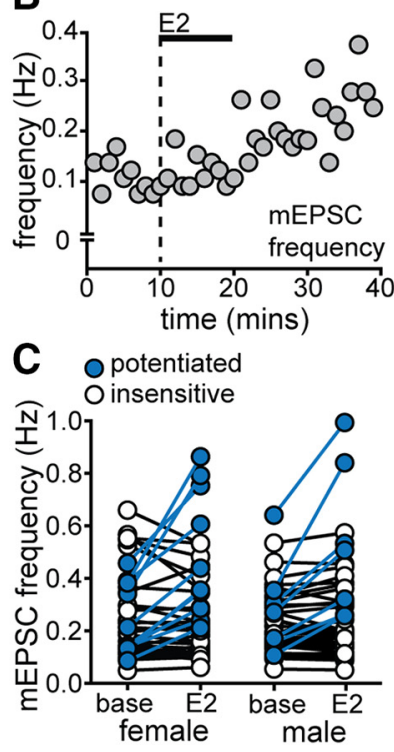

E mEPSC frequency
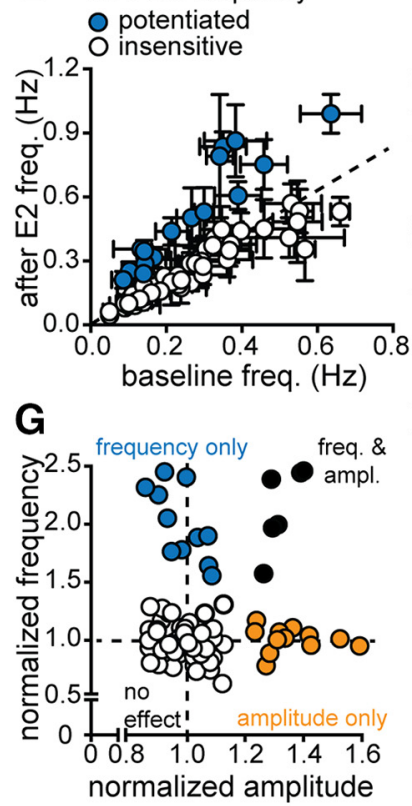
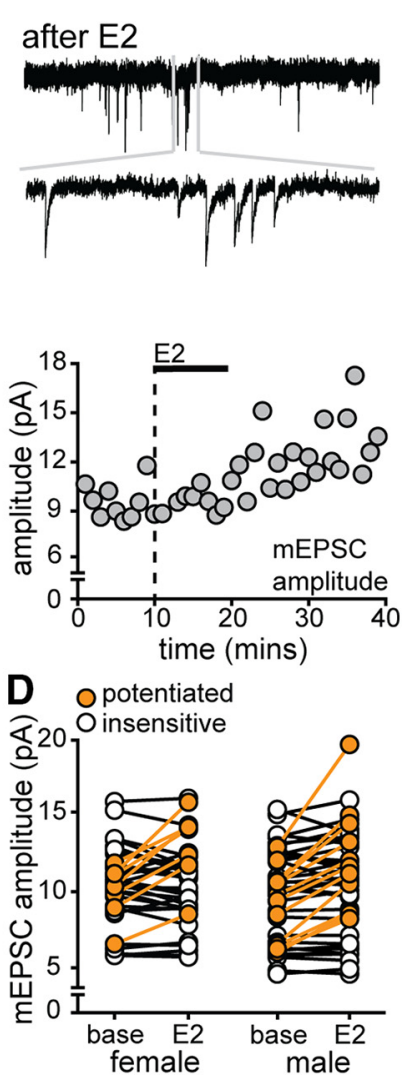

F mEPSC amplitude

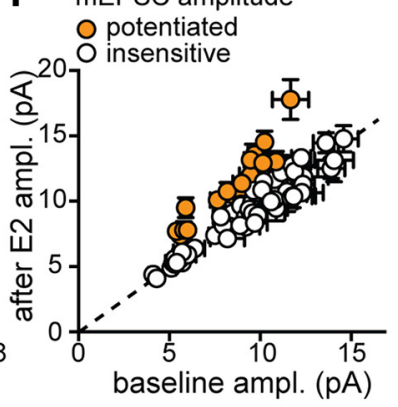

$\mathrm{H}$

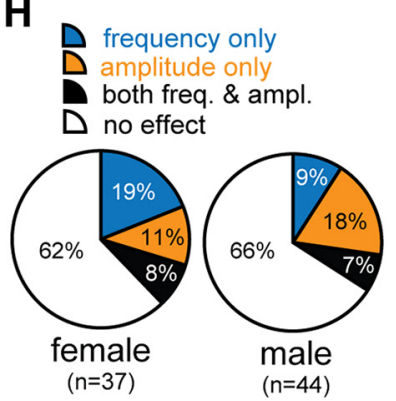

Figure 1. E2 acutely potentiates $m E P S C$ frequency and $m E P S C$ amplitude in both sexes. $A, B$, Sample experiment showing $(\boldsymbol{A}) \mathrm{mEPSC}$ recording during baseline and after $\mathrm{E} 2$ and $(B)$ the time course of the E2-induced increase in mEPSC frequency and $m E P S C$ amplitude in the same cell. C, Plots showing mean mEPSC frequency during baseline and after E2 for all cells in both females and males. Connected symbols represent data from an individual cell. Colored symbols represent the subset of cells in which within-cell $t$ tests showed a significant effect of $E 2$. White symbols represent cells with no significant effect of $\mathrm{E} 2$ (also in $\boldsymbol{D}-\boldsymbol{G})$. $\boldsymbol{D}$, Plots showing mean mEPSC amplitude during baseline and after E2 for the same cells as in $\boldsymbol{C} . \boldsymbol{E}, \boldsymbol{F}$, Plotting mean ( \pm SEM) mEPSC frequency $(\boldsymbol{E})$ or amplitude $(\boldsymbol{F})$ after $E 2$ versus during baseline for each cell shows that E2 potentiated $\mathrm{mEPSC}$ frequency and/or amplitude in cells that began with a wide range of baseline values. $\mathbf{G}$, Plotting the

ing, a $z$-stack ( $1 \mu \mathrm{m}$ step size) was taken through the dendrite and the entire dendritic tree for morphological measurements.

Controls to rule out the effects of MNI-glutamate or OGB on 2pEPSCs included omitting or washing out MNI-glutamate, which eliminated observable 2pEPSCs, and omitting OGB from the recording pipette during recording, which did not affect 2 pEPSC parameters. To demonstrate that responses were mediated by glutamate receptors, some recordings were made with CNQX (25 $\mu \mathrm{M}$, Tocris Bioscience) and APV $(20 \mu \mathrm{M}$, Tocris Bioscience) added to the bath to block AMPA and NMDA receptors, respectively, which eliminated $2 \mathrm{pEPSCs}$. APV alone reduced $2 \mathrm{pCaT}$ amplitude by $\sim 75 \%$, with no effect on 2 pEPSC amplitude, indicating that NMDA receptors are a principal source of calcium detected in $2 \mathrm{p}$ glutamate uncaging experiments. In $2 p$ experiments, we also varied the distance between the uncaging spot and the visible edge of a targeted spine and confirmed that uncaging further than $0.5 \mu \mathrm{m}$ from a spine failed to evoke a 2 pEPSC or $2 \mathrm{pCaT}$.

Data analysis. Electrophysiological analyses were performed offline using Clampfit (version 10.4.06), Minianalysis software (version 6.0, Synaptosoft Inc), Neuromatic (Igor Pro version 2.0) and/or custom scripts in MATLAB (The MathWorks, version R2014b). Line scans were analyzed using an ImageJ plugin for line scan analysis (Prairie, version 4.4). Statistical tests were performed in Graphpad PRISM software (version 7.0b), Statview (version 5.0.1) or MATLAB, and $\alpha$ was set at 0.05 . The minimum threshold for accepted EPSC amplitudes was determined individually for each recording and was set at the average noise plus $3 \times$ the SD (typically 3-7 pA).

Unpaired two-tailed Student's $t$ tests were used to determine whether individual cells or spines were responsive to E2 or an ER-selective agonist. Baseline values for each parameter were averaged per minute during 10-15 min of recording in aCSF, and values for each treatment were averaged per minute from data recorded 5-15 min after its application. The magnitude of E2 or ER-selective agonist effect on each cell or spine was then calculated by comparing each measure after treatment with the same measure immediately preceding that treatment. Group effects on mEPSCs, 2pEPSCs, and 2pCaTs were determined from individual cell or spine measurements using paired, two-tailed $t$ tests or by ANOVA on normalized effects as indicated in Results. $\chi^{2}$ tests or Fisher's exact tests (when the contingency table contained fewer than 10 observations) were used to determine whether the fraction of E2 or ER-agonist responsive cells or spines differed between males and females or among treatments. Pearson's correlation was calculated to investigate the relationship between E2 responsiveness of a spine and distance to the soma or to neighboring spines.

\section{Results}

Both presynaptic and postsynaptic mechanisms contribute to acute E2-induced excitatory synaptic potentiation

We first investigated presynaptic versus postsynaptic mechanisms of E2-induced synaptic potentiation by recording mEPSCs in CA1 pyramidal cells before, during, and after 10 min application of E2 (100 nM) to hippocampal slices from adult gonadectomized male and female rats (Fig. $1 A, B$ ). All recordings were made in TTX to block action potential-dependent glutamate release. These experiments showed that E2 increased both mEPSC frequency and mEPSC amplitude, but often in different cells. As has been shown before in females (Smejkalova and Woolley, 2010 ), only a subset of CA1 pyramidal cells was responsive to E2. In the current study, E2 increased mEPSC frequency by $27 \pm 9 \%$ overall in females $\left(t_{(36)}=2.16, p=0.037\right)$ and $16 \pm 6 \%$ overall in males $\left(t_{(43)}=2.79, p=0.0078\right)$, driven by statistically signifi-

normalized change in mEPSC frequency versus amplitude for each cell shows that E2 rarely increased both mEPSC frequency and amplitude in the same cells (black); more often, E2 increased mEPSC frequency only (blue), mEPSC amplitude only (orange), or had no effect on $\mathrm{mEPSCs}$ (white). $\boldsymbol{H}$, The proportion of cells in each category of mEPSC response to E2 is similar in females and males. 
cant within-cell increases ranging from $56 \%$ to $145 \%$ in 10 of 37 cells in females and from $56 \%$ to $146 \%$ in 7 of 44 cells in males (Fig. 1C). Neither the fraction of responsive cells (10 of 37 in females, 7 of 44 in males, Fisher's exact test, $p=0.28$ ) nor the magnitude of E2 effect in responsive cells (109 $\pm 11 \%$ females, $98 \pm 12 \%$ males; $\left.F_{(1,30)}=0.514, p=0.47\right)$ differed by sex.

E2 also increased mEPSC amplitude. The overall effect of E2 was small, only $3 \pm 3 \%$ in females $\left(t_{(36)}=0.81, p=0.41\right)$ and $10 \pm 3 \%$ in males $\left(t_{(43)}=3.39, p=0.0015\right)$, but included substantial statistically significant within-cell increases in subsets of cells in each sex. Within-cell analyses showed that E2 increased mEPSC amplitude by $20 \%$ to $42 \%$ in 7 of 37 cells in females, and by $23 \%$ to $59 \%$ in 11 of 44 cells in males (Fig. $1 D$ ). As with mEPSC frequency, there were no sex differences in the fraction of cells that responded to E2 ( 7 of 37 in females, 11 of 44 in males, Fisher's exact test, $p=0.60$ ) or the magnitude of response among cells that showed a significant increase ( $31 \pm 3 \%$ females, $37 \pm 3 \%$ males; $\left.F_{(1,32)}=1.46, p=0.23\right)$.

None of the 81 cells recorded showed a statistically significant decrease in either mEPSC frequency or amplitude after E2, and E2responsive cells included those with both high and low initial mEPSC frequency (Fig. 1E) and mEPSC amplitude (Fig. 1F). This indicates that $\mathrm{E} 2$ responsiveness of mEPSCs and our ability to detect effects of E2 on mEPSCs were not influenced by baseline values. Together, mEPSC recordings indicated that E2-induced excitatory synaptic potentiation involves both presynaptic and postsynaptic mechanisms in both sexes. The increase in mEPSC frequency likely reflects increased presynaptic glutamate release probability, shown previously in females (Smejkalova and Woolley, 2010), and the increase in mEPSC amplitude likely reflects increased postsynaptic sensitivity to glutamate, which has been inferred previously in studies using males (Kramár et al., 2009).

Interestingly, although E2 increased both mEPSC frequency and amplitude in both sexes, these effects typically occurred in different subsets of cells within each sex. Plotting the normalized effects of E2 on mEPSC frequency and amplitude for all cells individually (Fig. $1 G$ ) showed that only 6 of 81 cells responded to E2 with increases in both mEPSC frequency and amplitude. There were no sex differences in the fractions of cells showing increased mEPSC frequency, amplitude, or both (Fisher's exact test, $p>0.99$; Fig. $1 H$ ). That mEPSC frequency and amplitude were affected primarily in separate cells indicates that the presynaptic and postsynaptic components of E2-induced excitatory synaptic potentiation likely occur through independent mechanisms operating at distinct subsets of synapses. The relative timing of E2-induced increases in mEPSC frequency and amplitude support this idea. In the 6 cells in which both mEPSC frequency and amplitude were increased by E2, 2 showed the increase in frequency before the increase in amplitude, 2 showed the opposite, and 2 showed the increase in frequency and amplitude concurrently (data not shown).

\section{E2 acutely increases postsynaptic sensitivity to glutamate and potentiates glutamate-evoked calcium transients}

To test directly whether E2 increases postsynaptic sensitivity to glutamate and to investigate synapse specificity, in a different set of experiments, we recorded EPSCs evoked by $2 \mathrm{p}$ glutamate uncaging (2pEPSCs) at 1-6 dendritic spines along one segment of dendrite on 89 cells. In the 59 of these experiments in which we were able to evoke 2pEPSCs reliably from multiple spines (Fig. $2 A-C$ ), E2 increased 2pEPSC amplitude at a subset of dendritic spines on individual dendrites (Fig. 2D,E). These experiments were performed in both go- nadally intact and gonadectomized animals and because there was no significant difference in the effect of E2 on 2pEPSC amplitude in gonadally intact versus gonadectomized males $\left(F_{(1,115)}=0.035, p=\right.$ $0.85)$ or females $\left(F_{(1,108)}=2.82, p=0.098\right)$ data were combined within sex. Within-spine statistical analyses in all 89 cells showed that E2 significantly increased 2pEPSC amplitude evoked from 62 of 227 spines (Fig. $2 F$ ); no spines showed a statistically significant decrease in 2pEPSC amplitude after E2. As in mEPSC analysis, spines in which E2-potentiated 2pEPSCs included the full range of initial 2pEPSC amplitudes (Fig. $2 F$ ), and there was no sex difference in the fraction of responsive spines ( 30 of 116 in females, 32 of 111 in males, $\chi^{2}=0.25, p=0.62$; Fig. $2 G$ ). The magnitude of E2 potentiation in responsive spines also did not differ between males and females, although there was a statistical trend toward a larger effect of E2 in females $\left(F_{(1,61)}=3.32, p=0.07\right)$.

To investigate factors that might influence E2 sensitivity of individual spines, we considered whether the location of a spine within the dendritic tree was related to E2 sensitivity. However, there was no correlation between the distance of a spine to the soma and the magnitude of E2 response $(r=0.015, p=0.83)$ and no effect of dendritic branch order on the magnitude $\left(F_{(1,225)}=\right.$ $1.28, p=0.26)$ or likelihood $\left(\chi^{2}=0.022, p=0.88\right)$ of E2 response. Similarly, E2-potentiated spines were equally as likely to be proximal (33 of 62) or distal (29 of 62) to E2-insensitive spines on the same dendrite. We then investigated whether E2 sensitivity of a spine might be related to its proximity to other E2-sensitive spines. We considered pairs of spines on the same dendrite in which at least one spine was significantly potentiated by E2, determined the similarity of E2's effects between the two spines in each pair based on the ratio of the magnitude of E2's effect on 2pEPSC amplitude at each spine, and then compared this ratio with the linear distance between the spines (Fig. $2 H$ ). This showed a statistically significant relationship $(r=-0.53, p=0.0001$; Fig. $2 I)$, such that spines that were closer to each other had a more similar response to E2 than spines that were further apart. This relationship was essentially the same in males $(r=-0.55, p=0.001)$ and females $(r=$ $-0.49, p=0.001$ ). The observation that neighboring spines responded similarly to E2 could reflect cooperation of signaling between spines, such as through shared endoplasmic reticulum (Nishiyama et al., 2000) or another local dendritic factor that is involved in postsynaptic E2 potentiation.

The internal pipette solution used in 2pEPSC recordings contained the fluorescent calcium indicator, OGB. To investigate whether E2-induced 2pEPSC potentiation is associated with potentiation of postsynaptic calcium transients (2pCaTs), a line scan was taken over one spine and its parent dendrite during each recording (Fig. $3 A-C$ ). Analysis of E2induced changes in $\Delta \mathrm{F} / \mathrm{F}$ at each spine (Fig. $3 D$ ) showed that E2 increased 2 pCaT amplitude by $11.7 \pm 2.2 \%$ overall $\left(t_{(93)}=\right.$ $5.11, p=0.0001$, paired $t$ test), which was driven by statistically significant within-spine increases ranging from $14.4 \%$ to $102.3 \%$ in 23 of 94 spines (Fig. $3 E$ ). The E2-induced increase in $2 \mathrm{pCaT}$ amplitude was significant in both females $\left(t_{(47)}=3.92\right.$, $p=0.003)$ and males $\left(t_{(45)}=3.81, p=0.004\right)$ and was unaffected by gonadectomy in either sex ( $p$ values $>0.10)$. Similar to other measures, E2-responsive spines included a wide range of initial 2pCaT amplitudes (Fig. $3 E$ ) and the fraction of potentiated spines was similar between sexes ( 14 of 48 in females, 9 of 46 in males, $\left.\chi^{2}=1.17, p=0.28\right)$. Spines that showed potentiation of $2 \mathrm{pCaT}$ amplitude were a subset of those in which 2 pEPSC amplitude was potentiated by E2, and no spines showed an increase in $2 \mathrm{pCaT}$ amplitude without a corresponding increase in 2 pEPSC amplitude (Fig. $3 F$ ). 

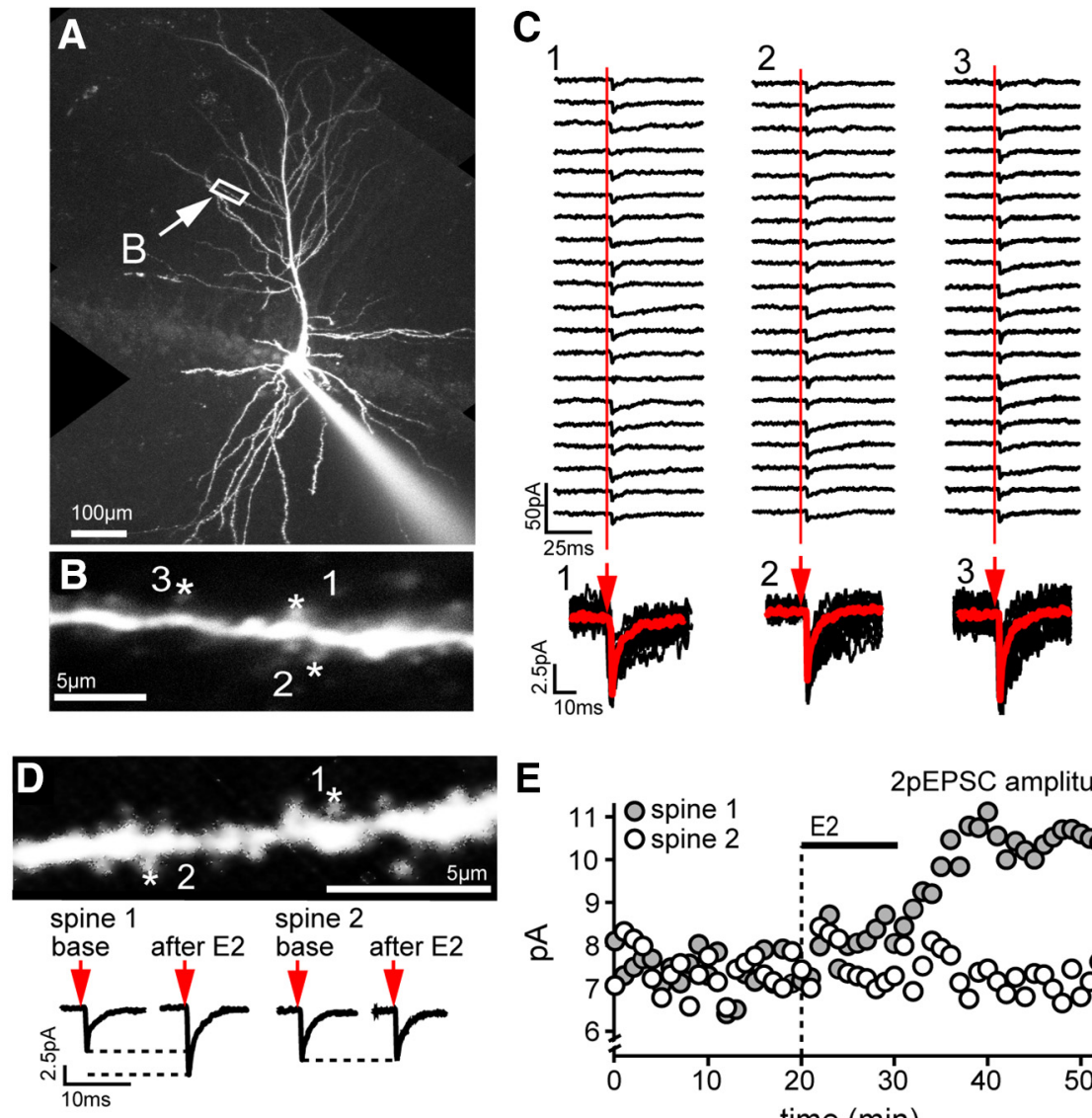

$\mathbf{F}$

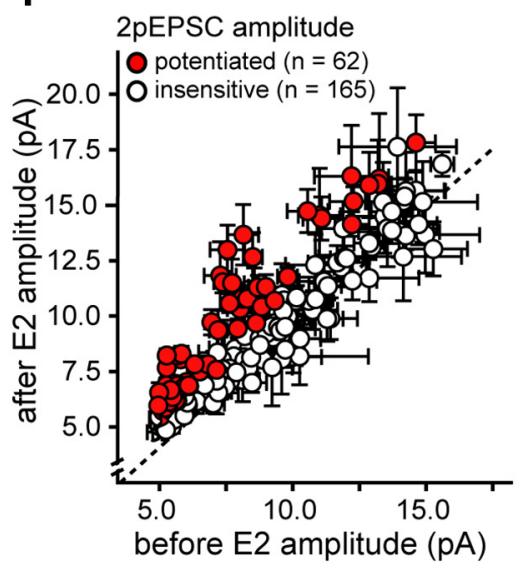

H
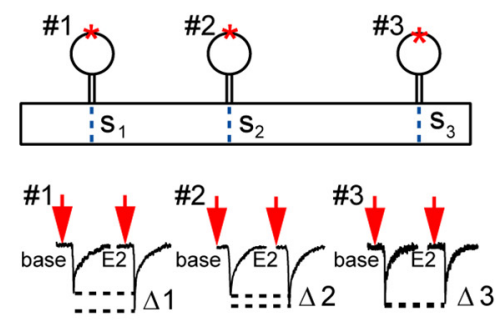

distance $=\mathrm{s}-\mathrm{s} \quad$ effect $=\Delta / \Delta$
E

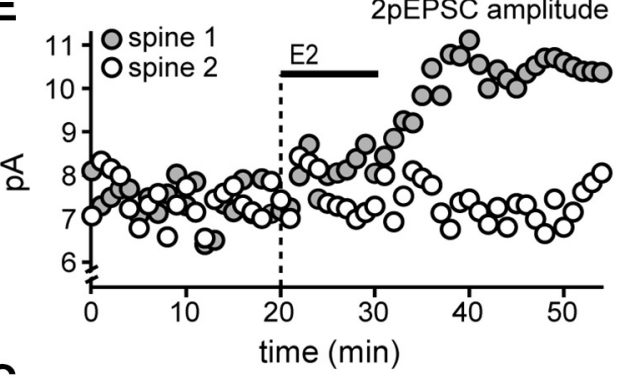

G

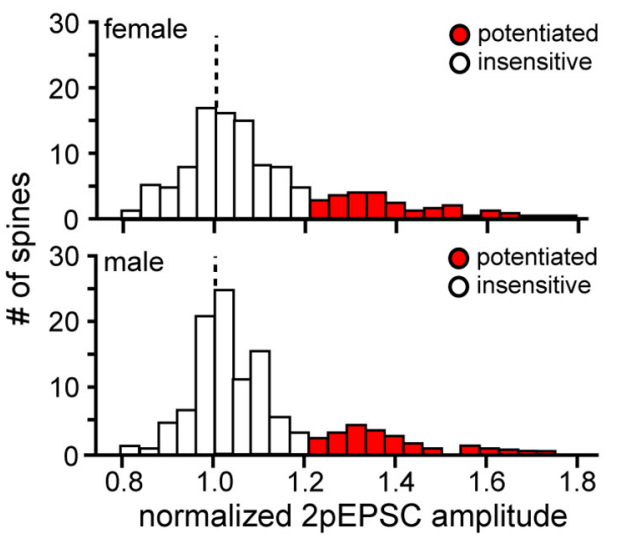

I

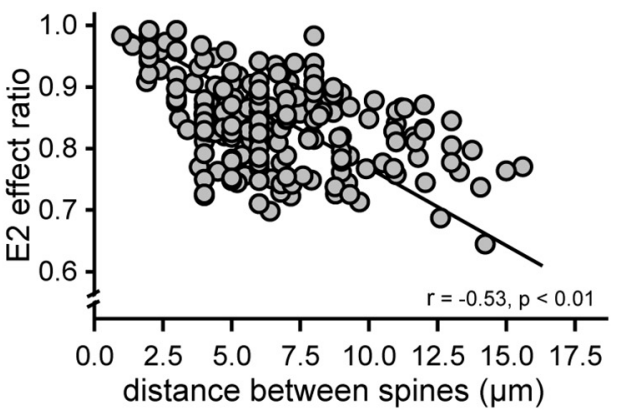

Figure 2. 2p-glutamate uncaging at individual spines shows that the postsynaptic effects of $E 2$ are synapse-specific. $A$, Image of a CA1 pyramidal cell during recording showing the dendrite targeted for $2 p$-glutamate uncaging (box). B, Highermagnification view of the dendrite showing three spines that were targeted for uncaging $\left.{ }^{*}\right)$. C, Currents from 20 individual sweeps during uncaging at the spines in $\boldsymbol{B}$. Flashes from the uncaging laser (red line) yielded 2pEPSCs consistently

Together, results from mEPSC, 2pEPSC, and $2 \mathrm{pCaT}$ recordings demonstrated that $\mathrm{E} 2$ potentiates excitatory synapses in the hippocampus through both presynaptic and postsynaptic mechanisms in both sexes, and that these effects likely occur independently at individual synapses. We next investigated the ERs that underlie presynaptic and postsynaptic effects of E2 in each sex.

$\mathrm{ER} \boldsymbol{\beta}$ activation potentiates excitatory synapses through distinct presynaptic versus postsynaptic mechanisms in females versus males

Previous studies have pointed to ER $\beta$ as mediating acute E2-induced potentiation of excitatory synapses in both females (Smejkalova and Woolley, 2010) and males (Kramár et al., 2009), albeit using different approaches and coming to different conclusions about the involvement of presynaptic versus postsynaptic mechanisms. To resolve this issue, we compared the effects of the $\mathrm{ER} \beta$ agonist, WAY200070 (WAY, $10 \mathrm{~nm}$ ), on mEPSC frequency and amplitude in identical experiments done in females (Fig. $4 A$ ) and males (Fig. 4B). When recordings lasted long enough, E2 was applied after washout of WAY to confirm E2 responsiveness of mEPSCs and/or test for non-ER $\beta$ mediated effects of E2.

Within-cell statistical tests showed that, in females, a 10 min application of WAY increased mEPSC frequency in 6 of 24 cells, by $91 \pm 15 \%$; in these 6 cells, E2 applied after WAY had no further effect on mEPSC frequency (Fig. 4C). The fraction of cells in which WAY increased mEPSC frequency (6

$\leftarrow$

throughout the recording; individual sweeps (black) are averaged (red) below. D, E, Sample experiment showing (D) two spines targeted for uncaging with averaged 2pEPSCs evoked at those spines during baseline and after $\mathrm{E} 2$ and $(\boldsymbol{E})$ the time course of the E2-induced increase in 2pEPSC amplitude at spine 1 with no change in 2pEPSC amplitude at spine 2 . $\boldsymbol{F}$, Plotting mean ( \pm SEM) 2pEPSC amplitude after E2 versus baseline for all spines tested shows that E2 potentiated $2 \mathrm{pEPSC}$ amplitude in spines that began with a wide range of baseline values. Red symbols represent the subset of spines in which within-spine $t$ tests indicated a significant effect of $\mathrm{E} 2$. White symbols represent spines with no significant effect of E2. $G$, Plotting distributions of the normalized change in $2 p E P S C$ amplitude after E2 for each sex shows no sex difference. $\boldsymbol{H}$, Schematic illustrating analysis of how the distance between spines on a dendrite influenced the similarity of their response to $E 2$. For each pair of spines, the ratio of normalized responses to E2 was calculated and compared with the linear distance between the spines. $I$, Plotting normalized response ratio for each spine pair versus linear distance between spines in a pair shows that spines that are closer together respond to $\mathrm{E} 2$ more similarly than spines that are further apart $(r=-0.53, p=0.0001)$. 

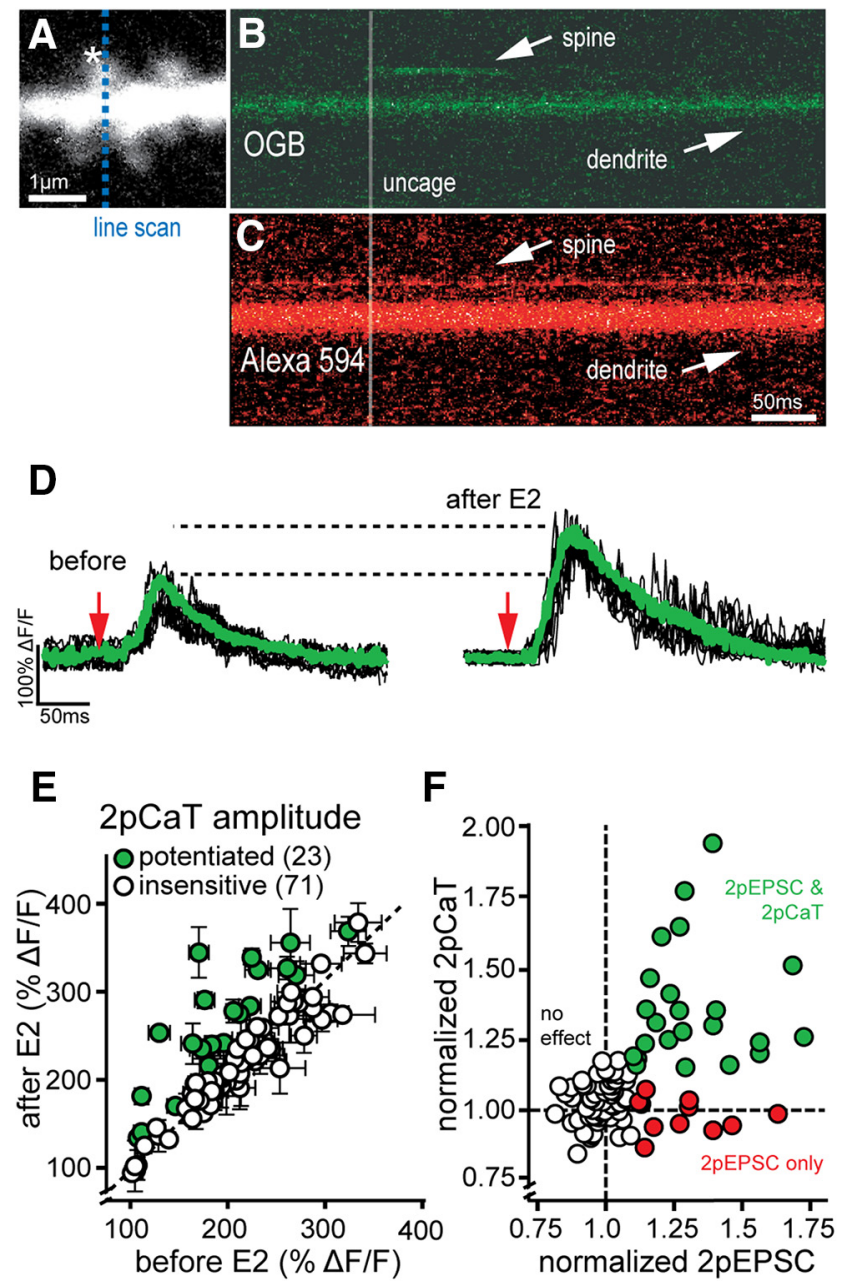

Figure 3. 2p-glutamate-evoked calcium transients in dendritic spines are potentiated by E2. $\boldsymbol{A}-\boldsymbol{C}$, At one spine per cell, a line scan (dashed blue line) was taken over the spine and its parent dendrite as shown in $\boldsymbol{A}$. 2p-glutamate uncaging at that spine evoked a transient increase in $0 G B$ fluorescence in the spine head $(B)$ with no change in Alexa-594 fluorescence $(\boldsymbol{C})$. D, The change in $0 G B$ over Alexa-594 fluorescence $(\triangle F / F)$ for the spine shown in $A-C$ plotted as a $2 p C a T$ before and after E2. Individual trials (black) were averaged (green). $\boldsymbol{E}$, Plotting mean ( \pm SEM) $2 p C a T$ amplitude after E2 versus baseline for each spine shows that $\mathrm{E} 2$ potentiated $2 \mathrm{pCaTs}$ in spines that began with a wide range of baseline values. Colored symbols represent the subset of spines in which within-spine $t$ tests indicated a significant effect of E2. White symbols represent spines with no significant effect of E2. $\boldsymbol{F}$, Plotting the normalized change in $2 \mathrm{pCaT}$ amplitude versus $2 \mathrm{pEPSC}$ amplitude within each spine shows that $2 p \mathrm{paTs}$ were potentiated in a subset of spines from which the 2 pEPSC was also potentiated by E2.

of 24) was similar to the fraction of cells in which E2 increased mEPSC frequency (10 of 37) (Fisher's exact test, $p>0.99$ ) Thus, WAY mimicked and occluded the E2-induced increase in mEPSC frequency in females. In contrast, in males, WAY failed to affect mEPSC frequency in any of 32 cells (Fig. 4D), but E2 applied after WAY washout increased mEPSC frequency in 1 cell, by $57 \%$, confirming its E2 responsiveness. Figure $4 E$ summarizes the different effects of WAY and E2 on mEPSC frequency in both sexes.

Measurements of mEPSC amplitude in the same recordings showed the converse results for females and males. In females, WAY had no effect on mEPSC amplitude in any of 24 cells (Fig. $4 F$ ), but E2 applied after WAY washout increased mEPSC amplitude in 3 cells, by $41 \pm 15 \%$. In males, WAY increased mEPSC amplitude in 5 of 32 cells, by $35 \pm 5 \%$, and this occluded a further increase in mEPSC amplitude when E2 was applied after WAY (Fig. 4G). The fraction of male cells in which WAY increased mEPSC amplitude (5 of 32) was statistically similar to the fraction of male cells in which E2 increased mEPSC amplitude (11 of 44 ) (Fisher's exact test, $p=0.40$ ). Figure $4 H$ summarizes different effects of WAY and E2 on mEPSC amplitude in both sexes.

Together, these findings confirm that ER $\beta$ activation acutely potentiates excitatory synapses in both sexes, but indicate that this potentiation occurs through distinct mechanisms in each sex. The WAY-induced increase in mEPSC frequency in females suggests that $\mathrm{ER} \beta$ activation increases presynaptic glutamate release probability as reported by Smejkalova and Woolley (2010), whereas the WAYinduced increase in mEPSC amplitude in males suggests that $\mathrm{ER} \beta$ activation increases postsynaptic glutamate sensitivity as reported by Kramár et al. (2009). At the same time, however, that E2 applied after WAY was able to produce the corresponding increase in mEPSC amplitude in females and frequency in males indicates that ER $\beta$ activation, alone, does not account for all aspects of E2-induced synaptic potentiation in either sex. We therefore tested how agonists of other known estrogen receptors, ER $\alpha$ and GPER1, affect mEPSCs in females and males.

ER $\alpha$ activation potentiates excitatory synapses through a presynaptic mechanism in males that is absent in females To investigate whether ER $\alpha$ plays a role in E2-induced synaptic potentiation, we tested the effect of the ER $\alpha$ agonist, PPT (100 nM), on mEPSC frequency and amplitude in females (Fig. 5A) and males (Fig. 5B). As with experiments using WAY, when the recording lasted long enough, E2 was applied after PPT washout to confirm E2 responsiveness and/or test for non-ER $\alpha$-mediated effects of E2.

Within-cell statistical comparisons showed that a $10 \mathrm{~min}$ application of PPT had no effect on mEPSC frequency in any of 20 cells from females. When E2 was applied to these cells after PPT washout, mEPSC frequency increased in 6 cells, by $69 \pm 12 \%$ (Fig. 5C). The lack of PPT effect on mEPSC frequency in cells that subsequently responded to E2 argues against ER $\alpha$ as being involved in the E2-induced increase glutamate release probability in females, corroborating results of a previous study (Smejkalova and Woolley, 2010). In contrast, PPT robustly increased mEPSC frequency in males. In 7 of 33 recordings in males, PPT increased mEPSC frequency, by $96 \pm 13 \%$ (Fig. 5D). In contrast to the effect of WAY on mEPSC frequency in females, however, the effect of PPT on mEPSC frequency in males was transient; mEPSC frequency returned to baseline during PPT washout. In 5 of the 6 PPT-responsive cells in which E2 was applied after PPT, mEPSC frequency increased again in E2 whereas E2 had no effect in any of the cells that had not responded to PPT. The fraction of male cells in which PPT increased mEPSC frequency ( 7 of 33) was statistically similar to the fraction of male cells in which E2 increased mEPSC frequency ( 7 of 44) (Fisher's exact test, $p=0.57$ ). Thus, PPT mimicked the E2-induced increase in mEPSC frequency in males, indicating that $\operatorname{ER} \alpha$ mediates the E2-induced increase in glutamate release probability in males. Figure $5 E$ summarizes mEPSC frequency results from experiments with PPT and E2 in both sexes.

Measurements of mEPSC amplitude in the same recordings showed no effect of PPT in any of the 20 cells in females (Fig. 5F) or 33 cells in males (Fig. 5G). When E2 was applied after PPT washout, mEPSC amplitude increased significantly in 2 of 20 cells from females, by $25 \pm 5 \%$, and 5 of 32 cells from males, by $39 \pm$ $3 \%$. Thus, mEPSC amplitude was responsive to E2 in cells that showed no effect of PPT on mEPSC amplitude. Figure $5 \mathrm{H}$ summarizes mEPSC amplitude results from experiments with PPT and E2 in both sexes. The absence of any effect of PPT on mEPSC 
A

female
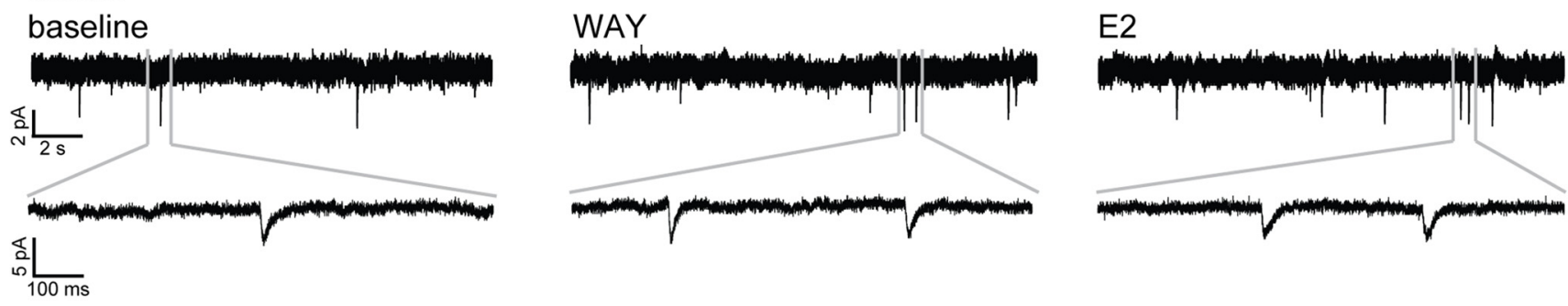

B

male

baseline

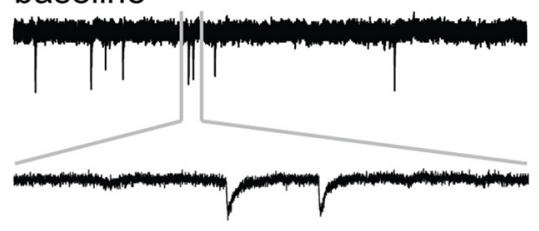

WAY

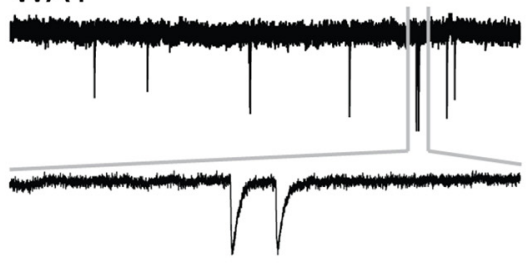

C mEPSC frequency

female

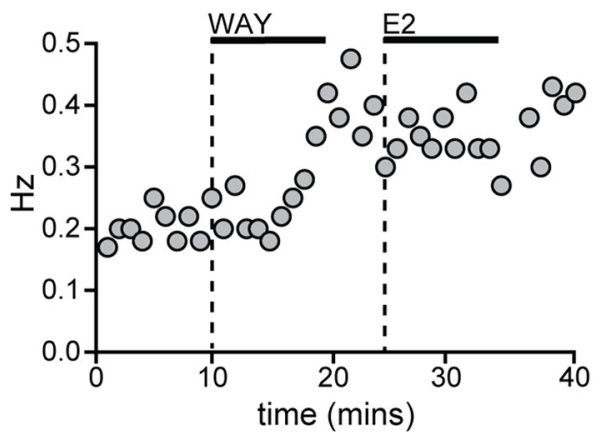

F mEPSC amplitude

female

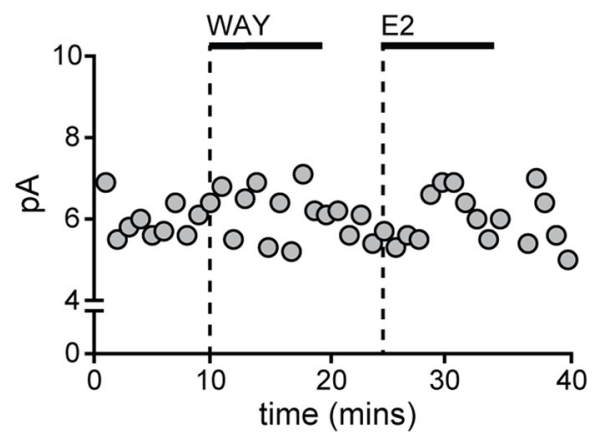

D mEPSC frequency male

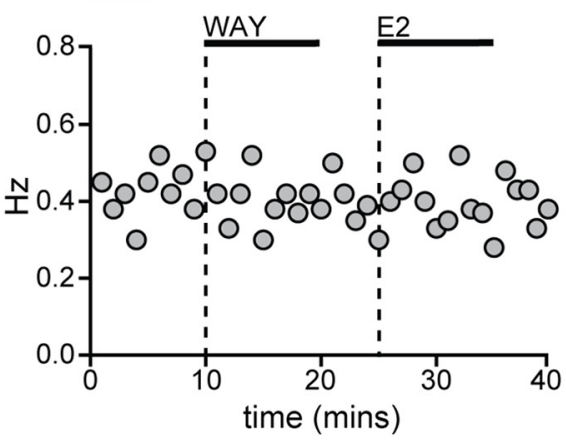

G

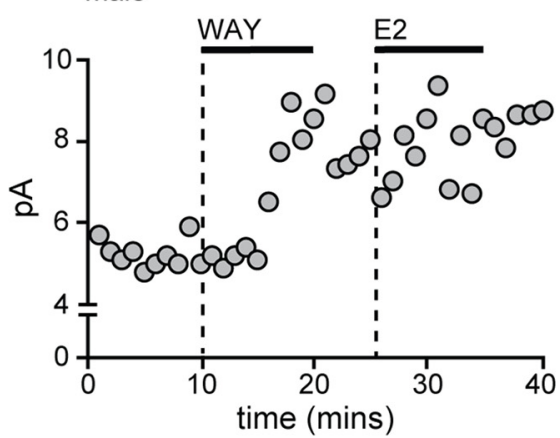

E2

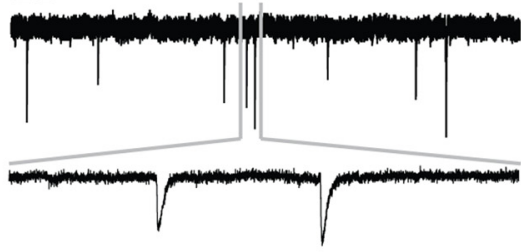

E mEPSC frequency

O potentiated $O$ insensitive

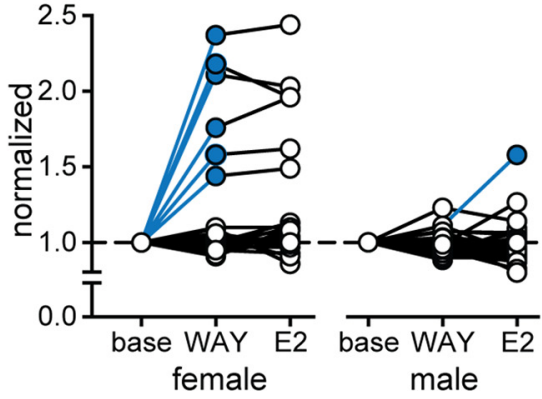

H mEPSC amplitude

O potentiated

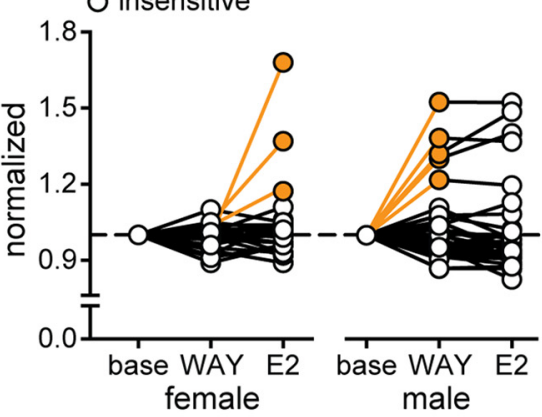

Figure 4. The ER $\beta$ agonist WAY200070 acutely potentiates mEPSC frequency in females and mEPSC amplitude in males. $A, B$, Sample mEPSC recordings during baseline, after WAY, and after E2 in a female $(\boldsymbol{A})$ and a male ( $\boldsymbol{B})$ cell. $\boldsymbol{C}$, Time course of mEPSC frequency changes for the same female cell as in $\boldsymbol{A}$ showing that WAY acutely increased mEPSC frequency and that E2 after WAY had no further effect. $\boldsymbol{D}$, Time course of mEPSC frequency changes for the same male cell as in $\boldsymbol{B}$ showing that WAY had no effect on mEPSC frequency. $\boldsymbol{E}$, Summary of mEPSC frequency analysis in female and male experiments with WAY. Colored symbols represent points in the experiment in which within-cell ttests indicated a significant difference from the preceding condition (also in $\boldsymbol{H}$ ). $\boldsymbol{F}$, Time course of $\mathrm{mEPSC}$ amplitude changes for the same female cell as in $\boldsymbol{A}$ showing that WAY had no effect. G, Time course of mEPSC amplitude changes for the same male cell as in $\boldsymbol{B}$ showing that WAY acutely increased mEPSC amplitude and that E2 after WAY had no further effect. $\boldsymbol{H}$,Summary of $m E P S C$ amplitude analysis in female and male experiments with WAY. There were no female cellstested with WAY that showed both a WAY-induced increase in $m E$ EPSC frequency and an E2-induced increase in mEPSC amplitude. Similarly, no male cells showed both a WAY-induced increase in mEPSC amplitude and an E2-induced increase in mEPSC frequency.

amplitude in either sex argues against a role for $\mathrm{ER} \alpha$ in the effect of E2 to increase postsynaptic sensitivity to glutamate.

Together, results from experiments with WAY and PPT showed that activation of $\mathrm{ER} \beta$ and $\mathrm{ER} \alpha$ together can account for most, but not all, components of E2-induced excitatory synaptic potentiation. The E2-induced increase in mEPSC frequency can be replicated by $\mathrm{ER} \beta$ activation in females and by $\mathrm{ER} \alpha$ activation in males; the E2-induced increase in mEPSC amplitude can be replicated by ER $\beta$ activation in males, but not in females. This leaves open the question of what ER subtype accounts for the E2-induced increase in mEPSC amplitude in females. One possibility is GPER1. G1, a GPER1 agonist, has been shown to increase 
A

female

baseline

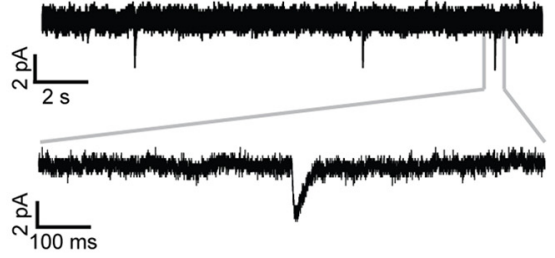

B

male

baseline

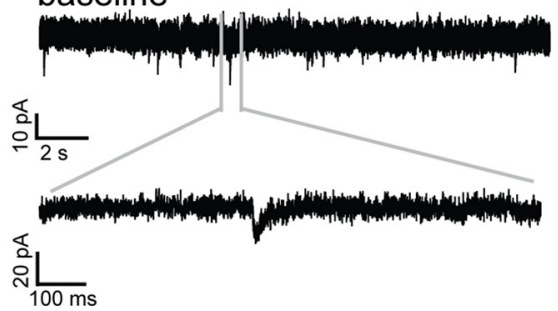

C mEPSC frequency female

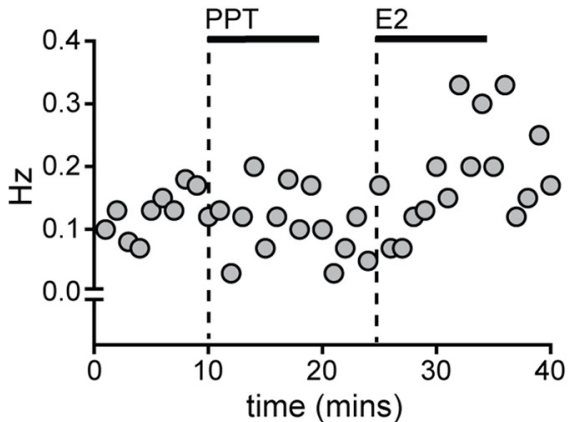

F mEPSC amplitude female

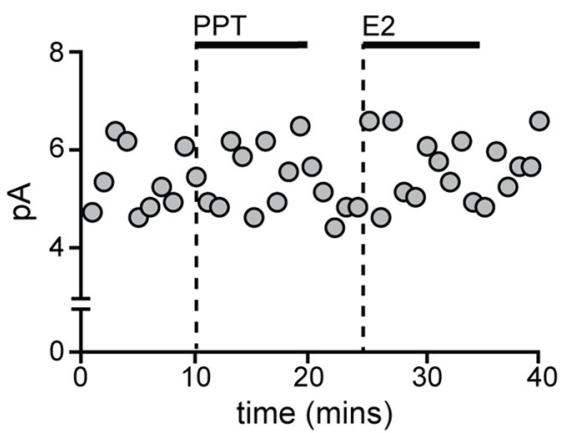

\section{PPT}

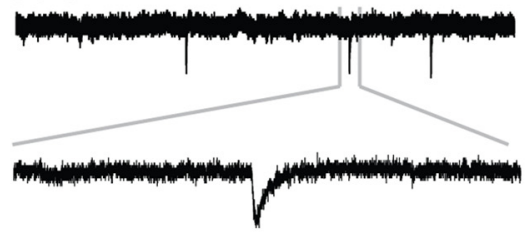

E2

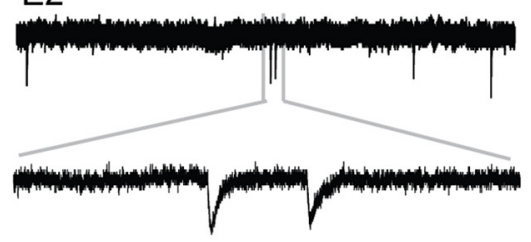

\section{PPT}

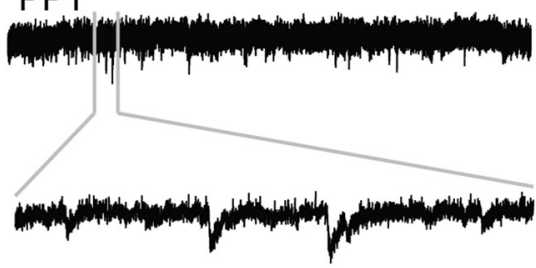

D mEPSC frequency

male

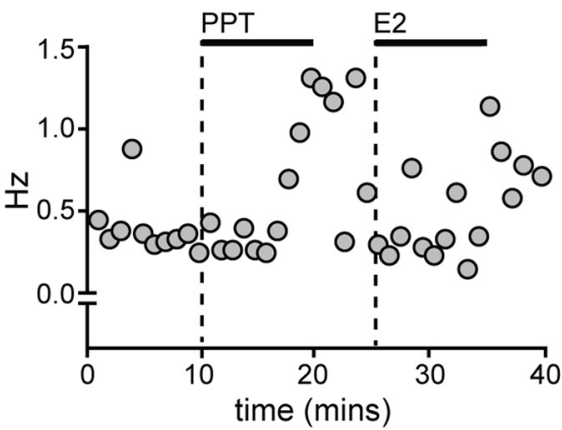

G mEPSC amplitude male

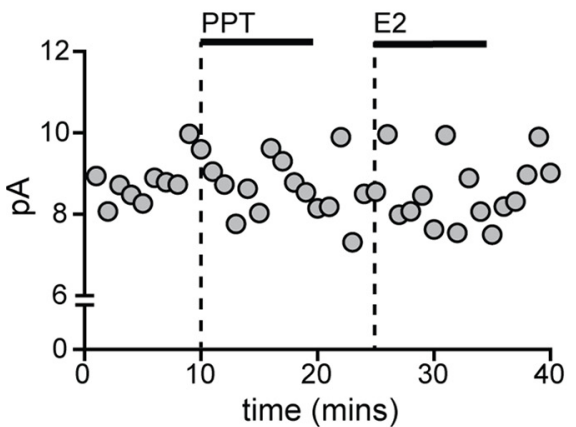

\section{E2}

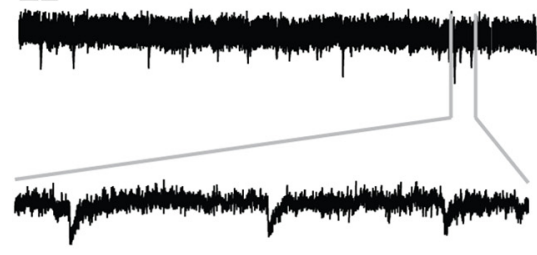

E

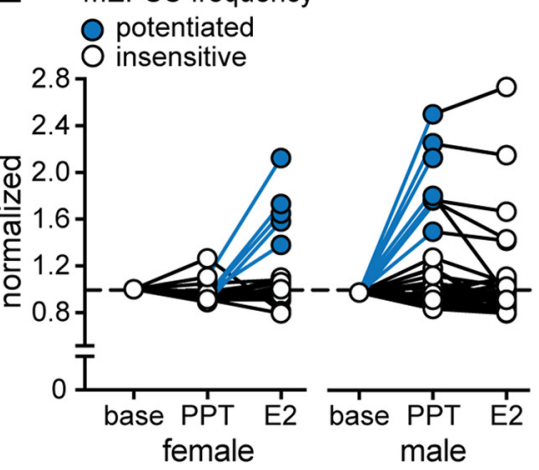

H mEPSC amplitude O potentiated

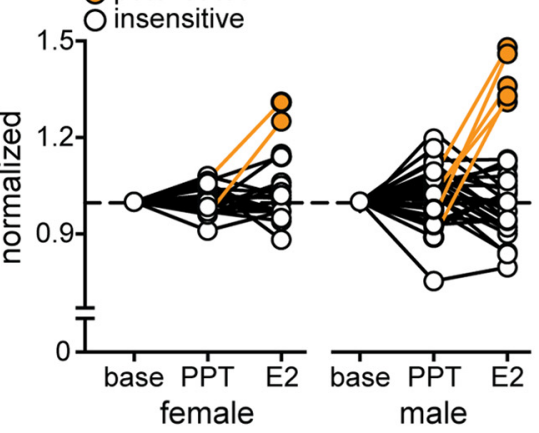

Figure 5. The ER $\alpha$ agonist PPT has no effect on $m E P S C$ in females but acutely potentiates $m E P S C$ frequency in males. $A, B$, Sample $m E P S C$ recordings during baseline, after PPT, and after E2 in a female $(\boldsymbol{A})$ and a male $(\boldsymbol{B})$ cell. $\boldsymbol{C}$, Time course of mEPSC frequency changes for the same female cell as in $\boldsymbol{A}$ showing that PPT had no effect on $m$ EPSC frequency but that E2 applied after PPT increased $m E P S C$ frequency, confirming that mEPSC frequency in this cell was responsive to E2. $\boldsymbol{D}$, Time course of mEPSC frequency changes for the same male cell as in $\boldsymbol{B}$ showing that PPT acutely (and transiently) increased mEPSC frequency and that E2 after PPT increased mEPSC frequency similarly to PPT. $\boldsymbol{E}$, Summary of mEPSC frequency analysis in female and male experiments with PPT. Colored symbols represent points in the experiment in which within-cell $t$ tests indicated a significant difference from the preceding condition (also in $\boldsymbol{H}$ ). $\boldsymbol{F}$, Time course of $m E$ EPSC amplitude changes for the same female cell as in $\boldsymbol{A}$ showing that PPT had no effect on mEPSC amplitude. G, Time course of mEPSC amplitude changes for the same male cell as in $\boldsymbol{B}$ showing that PPT had no effect on mEPSC amplitude. $\boldsymbol{H}$, Summary of mEPSC amplitude analysis in female and male experiments with PPT. There were no female tested with PPT that showed an E2-induced increase in both $\mathrm{mEPSC}$ frequency and amplitude and only one male cell showed both a PPT-induced increase in mEPSC frequency and an E2-induced increase in mEPSC amplitude.

field EPSP amplitude (Lebesgue et al., 2010) or slope (Kumar et al., 2015) in extracellular recordings in CA1 and to increase evoked EPSC amplitude in a subset of whole-cell recordings of CA1 pyramidal cells in females (Lebesgue et al., 2009; Smejkalova and Woolley, 2010).
GPER1 activation potentiates excitatory synapses through a postsynaptic mechanism in females that is absent in males To investigate the role of GPER1 in E2-induced synaptic potentiation, we tested the effects of G1 (100 nM) on mEPSCs in females (Fig. 6A) and males (Fig. 6B). As in experiments with 
A

female

baseline

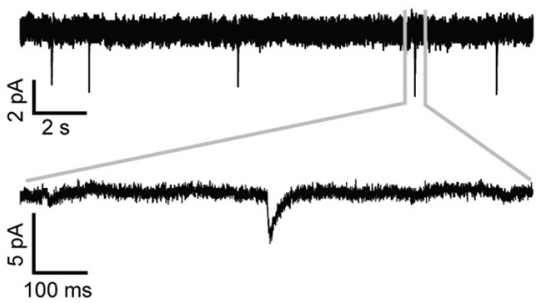

B

male

baseline

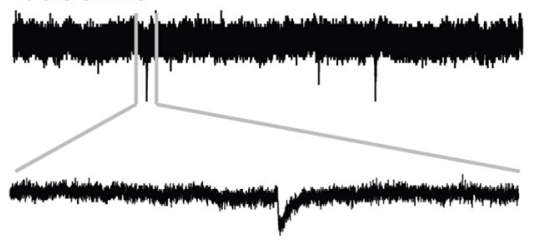

C mEPSC frequency

female

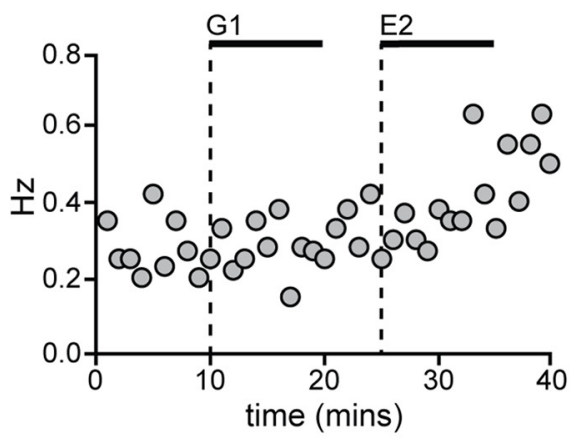

F mEPSC amplitude

female

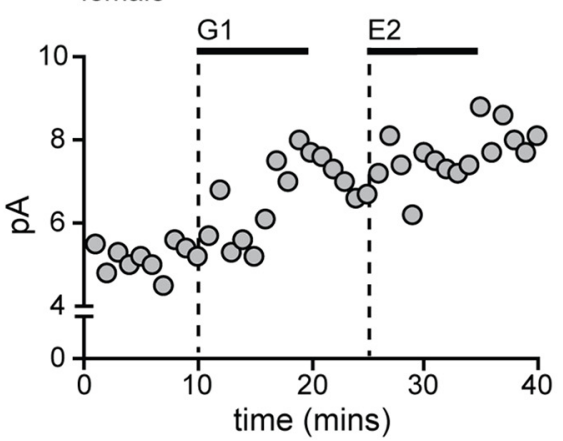

G1

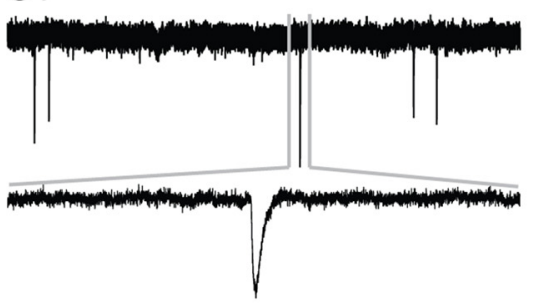

G1

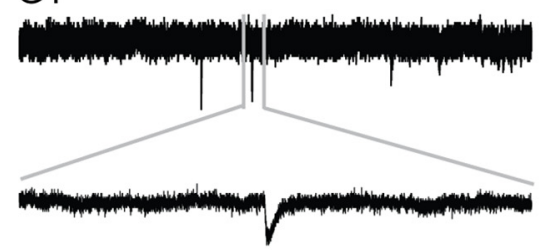

D mEPSC frequency

male

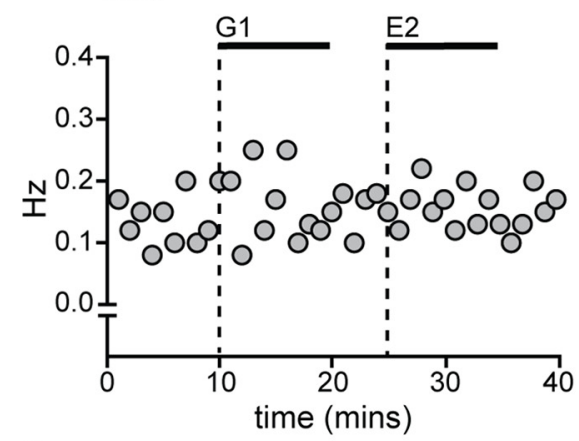

$\mathbf{G}$

mEPSC amplitude

male

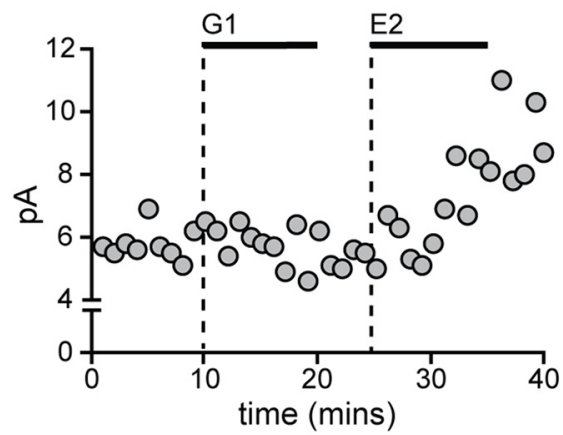

E2

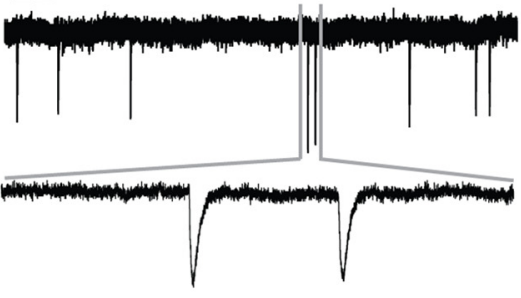

E2

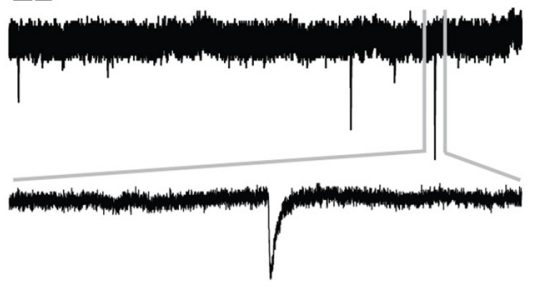

E mEPSC frequency

O potentiated

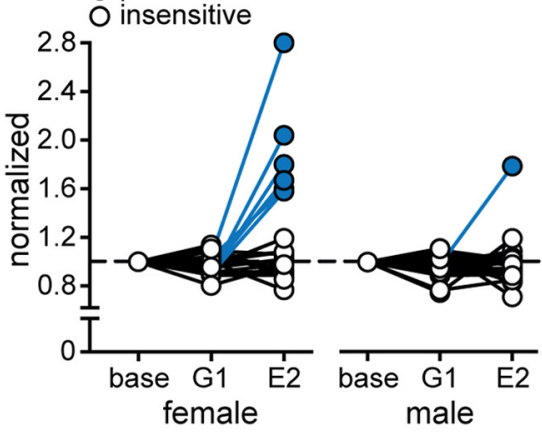

H mEPSC amplitude

O potentiated

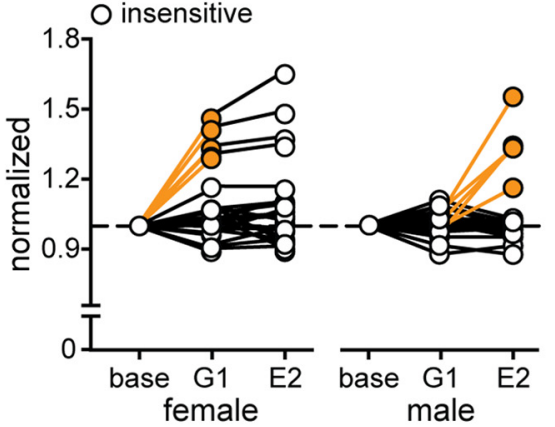

Figure 6. The GPER1 agonist $\mathrm{G} 1$ acutely potentiates $\mathrm{mEPSC}$ amplitude in females but has no effect on $\mathrm{mEPSC}$ in males. $\boldsymbol{A}$, $\boldsymbol{B}$, Sample $\mathrm{mEPSC}$ recordings during baseline, after $\mathrm{G} 1$, and after E2 in a female $(\boldsymbol{A})$ and a male $(\boldsymbol{B})$ cell. $\boldsymbol{C}$, Time course of mEPSC frequency changes for the same female cell as in $\boldsymbol{A}$ showing that G1 had no effect on $\mathrm{mEPSC}$ frequency but that E2 applied after $\mathrm{G} 1$ increased mEPSC frequency, confirming that mEPSC frequency in this cell was responsive to E2. D, Time course of mEPSC frequency changes for the same male cell as in $B$ showing that $\mathrm{G} 1$ had no effect on mEPSC frequency. $\boldsymbol{E}$, Summary of $\mathrm{mEPSC}$ frequency analysis in female and male cells with G1. Colored symbols represent points in the experiment in which within-cell $t$ tests indicated a significant difference from the preceding condition (also in $\boldsymbol{H}$ ). $\boldsymbol{F}$, Time course of $\mathrm{mEPSC}$ amplitude changes for the same female cell as in $\boldsymbol{A}$ showing that $\mathrm{G} 1$ acutely increased $\mathrm{mEPSC}$ amplitude and that E2 after $\mathrm{G} 1$ had no further effect. $\boldsymbol{G}$, Time course of mEPSC amplitude changes in the same male cell as in $\boldsymbol{B}$ showing that $\mathrm{G} 1$ had no effect on mEPSC amplitude but that E2 applied after $\mathrm{G} 1$ increased mEPSC amplitude, confirming that mEPSC amplitude in this cell was responsive to E2. There were no male cells tested with $\mathrm{G} 1$ that showed E2-induced increases in both mEPSC frequency and amplitude. $\boldsymbol{H}$, Summary of mEPSC amplitude analysis in female and male cells with $\mathrm{G} 1$.

WAY and PPT, E2 was applied after G1 washout to confirm E2 responsiveness and/or to test for non-GPER1-mediated effects of E2.

Within-cell statistical comparisons showed that $10 \mathrm{~min}$ application of G1 had no effect on mEPSC frequency in any of 23 cells from females (Fig. 6C) or 25 cells from males (Fig. 6D). When E2 was applied following G1 washout, mEPSC frequency increased in 6 of 22 cells from females, by $92 \pm 19 \%$, and in 1 of 25 cells from males, by $79 \%$. Thus, G1 failed to mimic the E2-induced increase in mEPSC frequency in cells in which mEPSC frequency 
did respond to E2, indicating that GPER1 does not modulate presynaptic glutamate release probability in either sex. Figure $6 E$ summarizes the effects of G1 and E2 on mEPSC frequency in both sexes.

Measurements of mEPSC amplitude in the same recordings showed that G1 increased mEPSC amplitude in 5 of 23 cells from females, by $36 \pm 3 \%$ (Fig. $6 F$ ); in the 22 of these cells in which E2 was applied after G1, there was no further effect on mEPSC amplitude. The fraction of G1-responsive cells in females (5 of 23) was statistically similar to the fraction of cells in which E2 increased mEPSC amplitude ( 7 of 37) (Fisher's exact test, $p>0.99$ ). Thus, G1 is sufficient to mimic and occlude the E2-induced increase in mEPSC amplitude in females, indicating that GPER1 activation increases postsynaptic sensitivity to glutamate in females. In contrast, and as expected from experiments in which $\operatorname{ER} \beta$ activation was able to fully mimic and occlude the E2induced increase in mEPSC amplitude in males, G1 failed to affect mEPSC amplitude in any of 25 cells from males (Fig. 6G). E2 increased mEPSC amplitude, by $34 \pm 6 \%$, in 5 of the 25 male cells in which E2 was applied after G1 washout confirming E2 responsiveness of mEPSC amplitude in these cells. Figure $6 \mathrm{H}$ summarizes the effects of G1 and E2 on mEPSC amplitude in both sexes. By demonstrating that GPER1 activation increases mEPSC amplitude specifically in females, the results of experiments with G1 provided the last piece of the puzzle to account for each presynaptic and postsynaptic component of E2-induced synaptic potentiation in both females and males.

\section{Postsynaptic sensitivity to glutamate and glutamate-evoked calcium transients are potentiated by GPER 1 in females and ER $\boldsymbol{\beta}$ in males}

Results of mEPSC recordings indicated that the E2-induced increase in postsynaptic sensitivity to glutamate is mediated by GPER1 in females and by ER $\beta$ in males. To corroborate these findings and to assess the synapse specificity of ER-selective agonist effects, we recorded 2pEPSCs and 2pCaTs in a different set of cells treated with WAY, PPT, or G1.

Within-spine statistical tests showed that WAY had no effect on 2pEPSC amplitude in any of 33 spines on 12 cells from females. In the subset of experiments in which we were able to apply E2 after WAY washout, E2 increased 2pEPSC amplitude in 8 of 21 spines, by $25.3 \pm 2.7 \%$, confirming that WAY failed to potentiate 2pEPSCs at E2-responsive spines in females. In contrast, in males, WAY did increase 2pEPSC amplitude in 12 of 51 spines on 13 cells, by $24.2 \pm 2.5 \%$. E2 had no further effect in any of the 34 spines in which E2 was applied following WAY washout. Thus, consistent with mEPSC amplitude results, WAY mimicked and occluded the effect of E2 to increase 2pEPSC amplitude in males. Also, as for mEPSCs, the fractions of WAY-potentiated and E2-potentiated spines in males were statistically similar $\left(\chi^{2}=0.50, p=0.48\right.$; Fig. $7 A$ vs Fig. $2 G)$. The effects of WAY and E2 on 2pEPSC amplitude in both sexes are summarized in Figure $7 A$.

The acute effect of WAY on 2 pCaTs paralleled 2pEPSC results. WAY failed to alter $2 \mathrm{pCaTs}$ in any of 13 spines from females but increased $2 \mathrm{pCaT}$ amplitude in 5 of 21 spines from males, by $37.3 \pm 6.9 \%$. In the subset of experiments in which E2 was applied after WAY washout, E2 increased 2pCaT amplitude in 3 of 11 spines from females, by $36.4 \pm 6.7 \%$, but had no further effect in 9 spines from males. The fraction of spines in which WAY potentiated $2 \mathrm{pCaTs}$ in males was similar to the fraction potentiated by E2 in males $\left(\chi^{2}=0.16, p=0.69\right)$. Thus, like for mEPSC and 2pEPSC amplitude, WAY mimicked and occluded the E2-induced increase in $2 \mathrm{pCaT}$ amplitude in males but had no effect on $2 \mathrm{pCaT}$ amplitude in females. The results of $2 \mathrm{pCaT}$ experiments with WAY and E2 are summarized in Figure $7 B$.

When we tested the effect of PPT on 2pEPSC amplitude (Fig. $7 C)$, within-spine statistical tests indicated that PPT was without effect in any of 39 spines on 11 cells from females, or in any of 54 spines on 15 cells from males. In the subset of recordings in which we applied E2 following PPT washout, E2 increased 2pEPSC amplitude in 12 of 32 spines from females, by $21.9 \pm 2.5 \%$, and in 15 of 42 spines from males, by $29.2 \pm 3.8 \%$. Thus, as for mEPSC amplitude, PPT failed to mimic the E2 potentiation of 2pEPSCs in either sex. PPT was also without effect on $2 \mathrm{pCaT}$ amplitude in any of 12 spines from females, or 20 spines from males (Fig. $7 D$ ). In the subset of experiments in which we applied E2 following PPT washout, E2 increased 2pCaT amplitude in 2 of 9 female spines, by $31 \%$ and $101 \%$, and in 4 of 16 male spines, by $31.9 \pm$ $1.5 \%$. These results were consistent with mEPSC recordings in which PPT had no effect on mEPSC amplitude in either sex.

Finally, we tested the effects of G1 on 2pEPSCs (Fig. 7E) and 2pCaTs (Fig. $7 F$ ) in both sexes. Within-spine comparisons showed that G1 increased 2pEPSC amplitude in 13 of 52 spines on 14 cells from females, by $27.4 \pm 3.0 \%$, but failed to affect 2pEPSC amplitude in any of 55 spines on 17 cells from males. Application of E2 after G1 washout had no further effect in any of 25 spines tested in females but increased 2pEPSC amplitude in 19 of 45 spines from males, by $16.3 \pm 2.1 \%$. The fraction of spines in which G1 increased 2pEPSC amplitude in females was statistically similar to the fraction of spines in which E2 had the same effect in females $\left(\chi^{2}=0.014, p=0.91\right.$; Fig. $7 E$ vs Fig. $\left.2 G\right)$. Thus, G1 mimicked and occluded E2 potentiation of 2pEPSCs in females, with no effect in males. This result was mirrored in analysis of 2pCaTs. Within-spine tests showed that G1 increased 2pCaT amplitude in 5 of 14 spines in females, by $37.4 \pm 7.8 \%$, but was without effect in any of 30 spines in males. In the subset of recordings in which we applied E2 after G1 washout, E2 failed to further affect 2pCaT amplitude in any of 6 spines from females but increased 2pCaT amplitude in 3 of 22 spines from males, by $41.0 \pm 3.1 \%$. As in other experiments, G1 potentiation of $2 \mathrm{pCaTs}$ in females occurred in a similar fraction of spines as E2 potentiation of 2 pCaTs in females $\left(\chi^{2}=0.22, p=0.64\right)$. Thus, as for WAY and PPT, 2p glutamate uncaging results with G1 were consistent with mEPSC recordings and showed that GPER1 activation mediates the postsynaptic effects of E2 in females.

\section{Discussion}

The results of this study demonstrate a latent sex difference in the mechanisms by which E2 acutely potentiates excitatory synaptic transmission in the hippocampus. We found that E2 increases both presynaptic glutamate release probability and postsynaptic sensitivity to glutamate in both sexes, but through distinct mechanisms that operate largely at separate synapses within each sex (Fig. 8). In females, E2 acts via $\mathrm{ER} \beta$ to increase presynaptic glutamate release probability and through GPER1 to increase postsynaptic sensitivity to glutamate. In males, E2 acts via ER $\alpha$ to increase glutamate release probability and through $\mathrm{ER} \beta$ to increase glutamate sensitivity. Remarkably, each presynaptic and postsynaptic component of E2-induced potentiation appears to be mediated exclusively by one ER subtype in each sex: $\mathrm{ER} \alpha, \mathrm{ER} \beta$, or GPER1 agonists each fully recapitulated one presynaptic or postsynaptic component of E2's effects in each sex and occluded any further effect of E2 on that component in that sex; applying E2 after an ER-selective agonist often pro- 
A

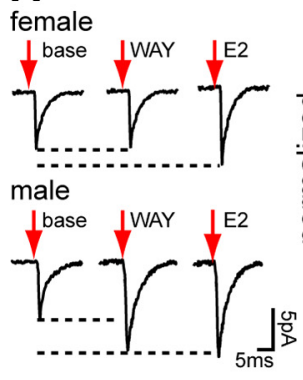

C

female

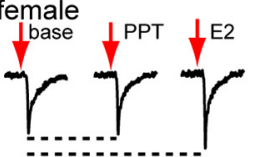

male

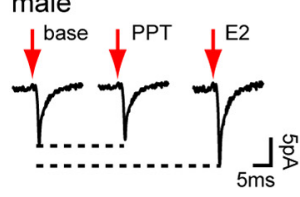

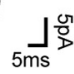

E

female

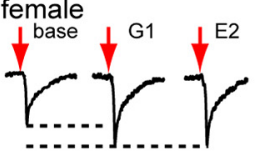

male

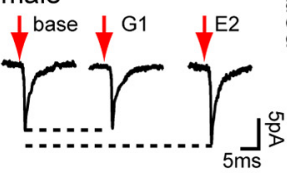

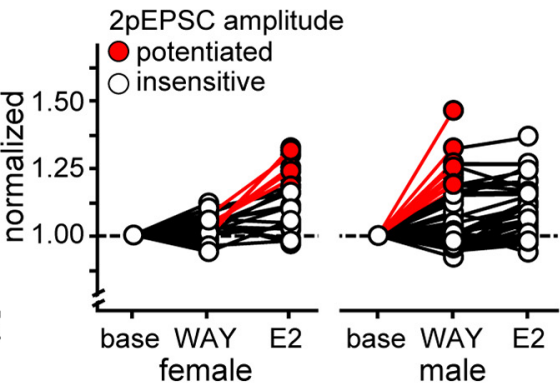

female
B

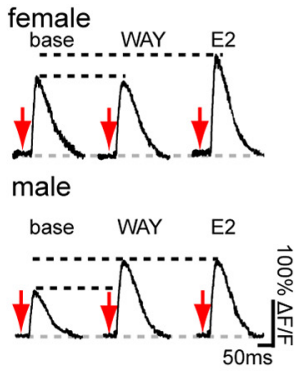

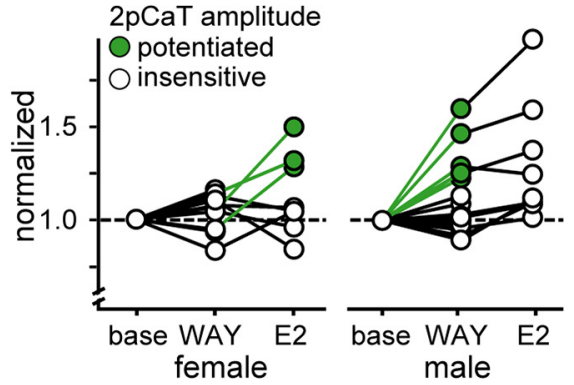

D

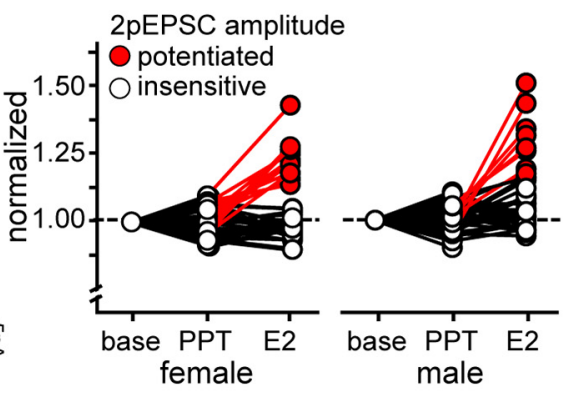

female
base PPT E2

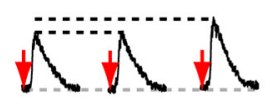

male
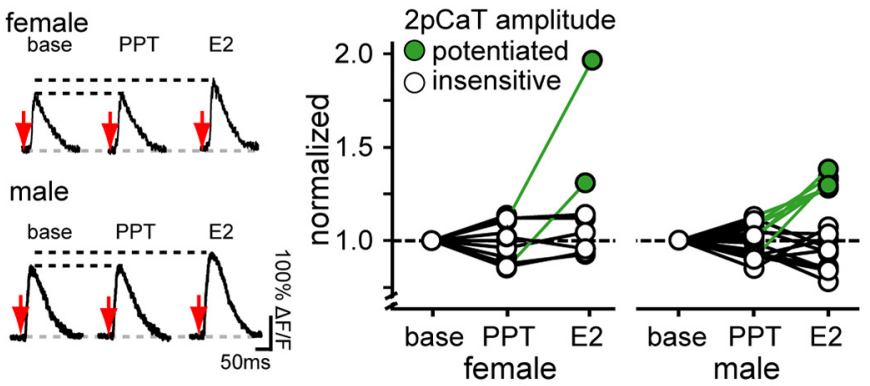

$\mathbf{F}$

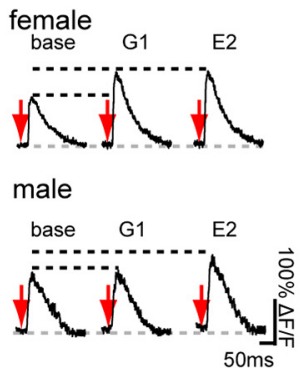

male
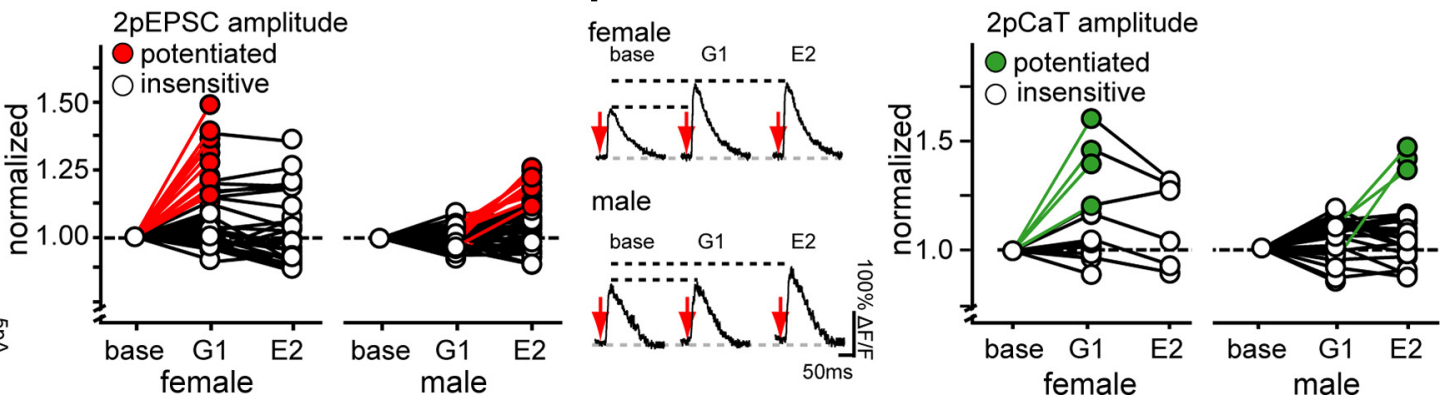

Figure 7. 2p-glutamate uncaging at individual spines confirms postsynaptic effects of the GPER1 agonist G1 in females and the ER $\beta$ agonist WAY200070 in males. $\boldsymbol{A}$, Sample recording of 2 pEPSCs from spines on a female (top) and a male (bottom) cell during baseline, after WAY, and after E2 and a summary of 2 pEPSC results with WAY in females and males. Colored symbols represent points in the experiment in which within-spine $t$ tests indicated a significant difference from the preceding condition (also in $\boldsymbol{B}-\boldsymbol{F}$ ). WAY increased $2 \mathrm{pEPSC}$ amplitude in a subset of spines from males and occluded a further effect of E2, whereas WAY had no effect on 2pEPSCs in females, even those that responded to E2 after WAY. $\boldsymbol{B}$, Representative $2 \mathrm{pCaTs}$ from the same spines shown in $\boldsymbol{A}$ during baseline, after WAY, and after E2 and a summary of $2 \mathrm{pCaT}$ results with WAY in females and males. $2 \mathrm{pCaT}$ analysis showed the same pattern as 2pEPSC analysis in that WAY increased 2pCaT amplitude only in males but had no effects in females, even in spines that responded to E2 after WAY. C, Sample 2pEPSCs from spines on a female (top) and a male (bottom) cell during baseline, after PPT, and after E2, and a summary of 2pEPSC results with PPT in females and males. PPT had no effects on 2 pEPSC amplitude in either sex, even in spines that responded to E2 after PPT. D, Sample 2pCaTs from the same spines shown in $\boldsymbol{C}$ during baseline, after PPT, and after E2 and a summary of 2pCaT experiments with PPT in females and males showing the same pattern as with 2pEPSCs. $E$, Sample 2pEPSCs from spines on a female (top) and a male (bottom) cell during baseline, after G1, and after E2, and a summary of 2pEPSC results with G1 in females and males. G1 increased 2pEPSC amplitude in a subset of spines from females and occluded any further effect of E2, whereas $\mathrm{G} 1$ had no effect on 2pEPSC amplitude in males, even those that responded to E2 after G1. $\boldsymbol{F}$, Sample 2pCaTs from the same spines shown in $\boldsymbol{E}$ during baseline, after G1, and after $\mathrm{E} 2$, and a summary of $2 \mathrm{pCaT}$ results with $\mathrm{G} 1$ in females and males. $2 \mathrm{pCaT}$ results mirrored $2 \mathrm{pEPSC}$ results in that G1 increased $2 \mathrm{pCaT}$ amplitude in a subset of spines from females, but had no effect in males, even in spines that responded to $E 2$ after $\mathrm{G} 1$. In all sample recordings, red arrow indicates the time of the uncaging.

duced the corresponding presynaptic or postsynaptic component that had not been activated by the ER agonist. This indicates a latent sex difference in which a particular stimulus produces the same functional endpoints through different mechanisms in each sex.

\section{Sex differences in mechanisms of acute E2-induced}

synaptic potentiation

Our study builds on previous work that has investigated mechanisms involved in acute E2-induced synaptic potentiation. Most previous studies have been done in only one sex, however, which has led to contradictions in the literature. For example, Kramár et al. (2009) studied males and came to the conclusion that E2-induced synaptic potentiation depends primarily on ER $\beta$ and occurs through a postsynaptic mechanism involving structural plasticity of the dendritic spine cytoskeleton. In contrast, Smejkalova and Woolley (2010) studied females, also found that $\operatorname{ER} \beta$ mediates E2-induced synaptic potentiation, but showed that this is due to an increase in presynaptic glutamate release probability. The current findings explain these apparently conflicting results by demonstrating a sex difference: ER $\beta$ activation increases postsynaptic sensitivity to glutamate in males and increases presynaptic glutamate release probability in females.

Other studies have implicated ER $\alpha$ and/or GPER1 in E2induced synaptic potentiation, again typically in one or the other 


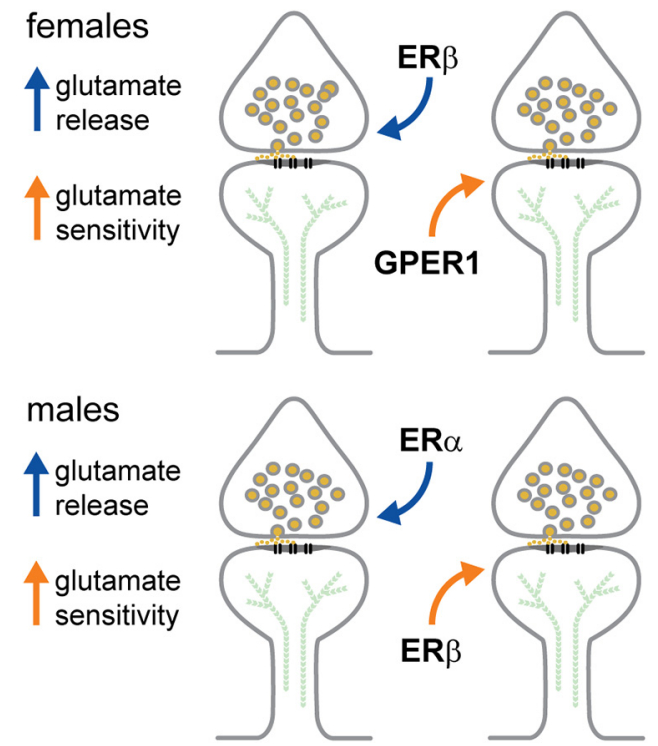

Figure 8. A latent sex difference in the mechanisms of E2-induced synaptic potentiation in the hippocampus. Our results support a model in which E2-induced synaptic potentiation is due to both an increase in presynaptic glutamate release probability and postsynaptic sensitivity to glutamate in each sex. In both sexes, the presynaptic and postsynaptic effects of $\mathrm{E} 2$ occur largely at separate groups of synapses. Despite these commonalities, however, a distinct combination of ER subtypes mediates E2's effects in each sex. In females, the presynaptic increase in glutamate release probability is mediated by $E R \beta$ and the postsynaptic increase in glutamate sensitivity is mediated by GPER1. In males, the presynaptic increase in glutamate release probability is mediated by ER $\alpha$ and the postsynaptic increase in glutamate sensitivity is mediated by $\operatorname{ER} \beta$.

sex. For example, Kumar et al. (2015) investigated effects of agonists for $\mathrm{ER} \beta, \mathrm{ER} \alpha$, and GPER1 using extracellular recordings from ovariectomized female mice. These authors found that the GPER1 agonist G1 produced robust potentiation of synaptic responses, whereas $\operatorname{ER} \beta$ and $\operatorname{ER} \alpha$ agonists each produced only modest potentiation. We found that the same concentration of G1 (100 nM) increased mEPSC, 2pEPSC, and 2pCaT amplitude in females, without affecting mEPSC frequency, indicating that the G1 effect measured by Kumar et al. (2015) was likely due to increased postsynaptic glutamate sensitivity. Based on our results, the effect of an ER $\beta$ agonist ( $1 \mu \mathrm{M}$ DPN) in the Kumar et al. (2015) study most likely resulted from increased glutamate release probability. The source of modest potentiation induced by an $\operatorname{ER} \alpha$ agonist is unresolved, however, as we found no effect of the same ER $\alpha$ agonist (100 nM PPT) in females. This could reflect a species difference and/or ER $\alpha$-dependent suppression of GABAergic inhibition, which occurs only in females (in rats, Huang and Woolley, 2012; Tabatadze et al., 2015), and may have influenced the recordings in Kumar et al. (2015). Further studies will be necessary to test these possibilities.

Synapse specificity in acute E2-induced synaptic potentiation Our results indicate that, even within one sex, distinct ERdriven mechanisms involved in the presynaptic versus postsynaptic aspects of synaptic potentiation operate largely at separate synapses. E2 increased both mEPSC frequency and amplitude in only $7-8 \%$ of recorded cells; in most cells, E2 increased either mEPSC frequency (9-19\%) or mEPSC amplitude (11-18\%), or had neither effect (62-66\%). 2p-glutamate uncaging at individual dendritic spines further demonstrated that the postsynaptic component of E2's effects is synapsespecific, not cell-wide, and that there is considerable heterogeneity in E2 responsiveness among spines. The E2-induced increase in 2pEPSC amplitude ranged from $15 \%$ to $72 \%$ and was variable even among spines on the same dendrite, although neighboring spines tended to respond similarly. The synapse specificity of E2's postsynaptic effects parallels results from a previous study in which stimulation of multiple nonoverlapping inputs to individual cells showed that the presynaptic component of potentiation is also input-specific (in females, Smejkalova and Woolley, 2010).

Synapse specificity of E2-induced synaptic potentiation is likely to be related, at least partly, to the heterogeneous distribution of extranuclear ERs that mediate rapid actions of E2. All three ERs studied here, ER $\alpha$ (Milner et al., 2001), ER $\beta$ (Milner et al., 2005), and GPER1 (Waters et al., 2015), have been localized to subsets of dendritic spines, excitatory axonal boutons, and glial processes within the CA1 region of the hippocampus using immunoelectron microscopy. Although the fraction of spines, boutons, or glia containing immunoreactivity for each extranuclear ER has not been reported, the heterogeneous distribution of ERs predicts that effects mediated by any one ER subtype should occur at only a subset of synapses, as we found. In the several studies that have investigated the subcellular localization of extranuclear ERs in both sexes (e.g., Waters et al., 2015 for GPER1; Mitterling et al., 2010 for $E R \beta$, in mice), some quantitative sex differences have been observed, but no qualitative differences have been reported that would account for the profound sex differences we observed in the sensitivity of presynaptic versus postsynaptic components of synaptic potentiation to ER-selective agonists. Thus, it is likely that the E2 responsiveness of a synapse requires both the relevant ER subtype and downstream signaling machinery that links ER activation to increased synaptic strength. Also, we found no differences in E2 responsiveness of synapses between gonadally intact and gonadectomized males or females in glutamate uncaging experiments. This indicates that circulating gonadal hormones do not affect acute postsynaptic E2 sensitivity of synapses, for example, by regulating extrasynaptic ERs, at least over the short time period tested in these experiments $(\sim 1$ week).

Most studies that have investigated downstream mechanisms of extranuclear ER signaling have been done in cell culture (Srivastava et al., 2013) and have focused either on coupling of membrane-associated $\mathrm{ER} \alpha$ or $\operatorname{ER} \beta$ to second messenger signaling cascades through interactions with $G$ proteincoupled receptors or signaling downstream of GPER1, which is itself a $G$ protein-coupled receptor. One consistent finding across multiple studies of acute E2 modulation of synapses from both sexes is involvement of the mitogen-activated protein kinase pathway (Lebesgue et al., 2009; Zadran et al., 2009; Kumar et al., 2015); beyond this, however, it is unclear which of the many pathways that are acutely activated by E2 contribute to acute E2-induced synaptic potentiation.

One important question to address in future studies will be to determine where males and females converge in the pathway(s) that link specific ERs with increased glutamate release probability and sensitivity. For example, it will be useful to know whether activation of ER $\beta$ in males and GPER 1 in females, both of which lead to increased postsynaptic sensitivity to glutamate, produce the same or different effects on AMPA receptor number and/or conductance, and whether through common or distinct signaling pathways. In males, E2 has been shown to increase surface expression of AMPA receptors (Zadran et al., 2009) as well as to promote postsynaptic actin polymerization through a Rho kinase-dependent increase in 
phosphorylated cofilin (Kramár et al., 2009), likely acting through ER $\beta$ (Babayan and Kramár, 2013). In females, GPER1 has been shown to interact with the postsynaptic scaffolding protein PSD95 (Akama et al., 2013), which could influence AMPA receptor dynamics at synapses (Nair et al., 2013). Whether GPER1 links to a similar Rho kinase/cofilindependent mechanism in females is not yet known, however.

\section{Potential significance of latent sex differences in mechanisms of rapid E2 signaling}

The observation of latent sex differences in mechanisms of synaptic modulation is reminiscent of De Vries' description of compensatory sex differences (De Vries, 2004), which posits that the significance of some sex differences may be to compensate for other sex differences, making males and females more similar at the behavioral level rather than more different. Our findings could be viewed in this way, in that the combination of ER- dependent synaptic strengthening mechanisms in each sex compensates for lack of the complementary ER-dependent synaptic strengthening mechanisms in the opposite sex.

For both sexes, understanding the significance of E2's acute actions will depend on identifying the circumstances under which estrogens are produced as neurosteroids and may therefore activate acute signaling endogenously. This is an active research area in our laboratory and others. Additionally, however, latent sex differences in mechanisms of acute estrogen actions in the brain are relevant to the development and testing of therapeutics that target ER subtypes selectively, such as ER $\beta$ agonists for Alzheimer's disease (Zhao et al., 2015) and other neurological or neuropsychiatric conditions (www.clinicaltrials.gov). Given our findings, it can be anticipated that ER subtype-selective compounds may have different effects in the brains of men and women.

\section{Correction}

\section{Correction: Oberlander and Woolley, $17 \boldsymbol{\beta}$-Estradiol Acutely Potentiates Glutamatergic Synaptic Transmission through Distinct Mechanisms in Males and Females}

Subsequent to publication of " $17 \beta$-Estradiol Acutely Potentiates Glutamatergic Synaptic Transmission through Distinct Mechanisms in Males and Females” by Joseph G. Oberlander and Catherine S. Woolley in The Journal of Neuroscience on pages 2677-2690 of the March 2, 2016 issue, the authors became aware of errors related to the mEPSC analyses in the paper. Therefore, to verify the results, two additional members of the senior author's laboratory, Anant Jain and Guangzhe Huang, repeated all mEPSC experiments in a separate cohort of an additional 238 cells. Importantly, these new experiments confirmed each of the findings of the study and the conclusions are unchanged. However, because there were quantitative differences between the published data and replication results, the mEPSC figures in the paper (Figs. 1, 4, 5, 6) have been replaced to represent data solely from the replication experiments. The text has been revised to update the numerical data and to indicate that mEPSC and 2-photon glutamate uncaging experiments were done in separate cells. The Acknowledgements have been updated to reflect the extensive contributions of Anant Jain and Guangzhe Huang. All other text is unchanged. Due to the number of locations in the article where the results needed to be updated to represent data solely from the replication experiments, this corrected version is being published.

DOI: 10.1523/JNEUROSCI.3011-17.2017

\section{References}

Akama KT, Thompson LI, Milner TA, McEwen BS (2013) Post-synaptic density-95 (PSD-95) binding capacity of G-protein-coupled receptor 30 (GPR30), an estrogen receptor that can be identified in hippocampal dendritic spines. J Biol Chem 288:6438-6450. CrossRef Medline

Babayan AH, Kramár EA (2013) Rapid effects of oestrogen on synaptic plasticity: interactions with actin and its signalling proteins. J Neuroendocrinol 25:1163-1172. CrossRef Medline

De Vries GJ (2004) Minireview. Sex differences in adult and developing brains: compensation, compensation, compensation. Endocrinology 145: 1063-1068. CrossRef Medline

Gu Q, Moss RL (1996) 17beta-estradiol potentiates kainate-induced currents via activation of the cAMP cascade. J Neurosci 16:3620-3629. Medline

Hojo Y, Hattori TA, Enami T, Furukawa A, Suzuki K, Ishii HT, Mukai H, Morrison JH, Janssen WG, Kominami S, Harada N, Kimoto T, Kawato S (2004) Adult male rat hippocampus synthesizes estradiol from pregnenolone by cytochromes P45017alpha and P450 aromatase localized in neurons. Proc Natl Acad Sci U S A 101:865-870. CrossRef Medline

Huang GZ, Woolley CS (2012) Estradiol acutely suppresses inhibition in the hippocampus through a sex-specific endocannabinoid and mGluRdependent mechanism. Neuron 74:801-808. CrossRef Medline
Kramár EA, Chen LY, Brandon NJ, Rex CS, Liu F, Gall CM, Lynch G (2009) Cytoskeletal changes underlie estrogen's acute effects on synaptic transmission and plasticity. J Neurosci 29:12982-12993. CrossRef Medline

Kumar A, Bean LA, Rani A, Jackson T, Foster TC (2015) Contribution of estrogen receptor subtypes, ERalpha, ERbeta, and GPER1 in rapid estradiol-mediated enhancement of hippocampal synaptic transmission in mice. Hippocampus 25:1556-1566. CrossRef Medline

Lebesgue D, Chevaleyre V, Zukin RS, Etgen AM (2009) Estradiol rescues neurons from global ischemia-induced cell death: multiple cellular pathways of neuroprotection. Steroids 74:555-561. CrossRef Medline

Lebesgue D, Traub M, De Butte-Smith M, Chen C, Zukin RS, Kelly MJ, Etgen AM (2010) Acute administration of non-classical estrogen receptor agonists attenuates ischemia-induced hippocampal neuron loss in middle-aged female rats. PLoS One 5:e8642. CrossRef Medline

MacLusky NJ, Walters MJ, Clark AS, Toran-Allerand CD (1994) Aromatase in the cerebral cortex, hippocampus, and mid-brain: ontogeny and developmental implications. Mol Cell Neurosci 5:691-698. CrossRef Medline

Milner TA, McEwen BS, Hayashi S, Li CJ, Reagan LP, Alves SE (2001) Ultrastructural evidence that hippocampal alpha estrogen receptors are located at extranuclear sites. J Comp Neurol 429:355-371. CrossRef Medline 
Milner TA, Ayoola K, Drake CT, Herrick SP, Tabori NE, McEwen BS, Warrier S, Alves SE (2005) Ultrastructural localization of estrogen receptor beta immunoreactivity in the rat hippocampal formation. J Comp Neurol 491:81-95. CrossRef Medline

Mitterling KL, Spencer JL, Dziedzic N, Shenoy S, McCarthy K, Waters EM, McEwen BS, Milner TA (2010) Cellular and subcellular localization of estrogen and progestin receptor immunoreactivities in the mouse hippocampus. J Comp Neurol 518:2729-2743. CrossRef Medline

Nair D, Hosy E, Petersen JD, Constals A, Giannone G, Choquet D, Sibarita JB (2013) Super-resolution imaging reveals that AMPA receptors inside synapses are dynamically organized in nanodomains regulated by PSD95. J Neurosci 33:13204-13224. CrossRef Medline

Nishiyama M, Hong K, Mikoshiba K, Poo MM, Kato K (2000) Calcium stores regulate the polarity and input specificity of synaptic modification. Nature 408:584-588. CrossRef Medline

Prange-Kiel J, Wehrenberg U, Jarry H, Rune GM (2003) Para/autocrine regulation of estrogen receptors in hippocampal neurons. Hippocampus 13:226-234. CrossRef Medline

Roselli CE, Horton LE, Resko JA (1985) Distribution and regulation of aromatase activity in the rat hypothalamus and limbic system. Endocrinology 117:2471-2477. CrossRef Medline

Smejkalova T, Woolley CS (2010) Estradiol acutely potentiates hippocampal excitatory synaptic transmission through a presynaptic mechanism. J Neurosci 30:16137-16148. CrossRef Medline

Srivastava DP, Woolfrey KM, Penzes P (2013) Insights into rapid modula- tion of neuroplasticity by brain estrogens. Pharmacol Rev 65:1318-1350. CrossRef Medline

Tabatadze N, Sato SM, Woolley CS (2014) Quantitative analysis of longform aromatase mRNA in the male and female rat brain. PLoS One 9:e100628. CrossRef Medline

Tabatadze N, Huang G, May RM, Jain A, Woolley CS (2015) Sex differences in molecular signaling at inhibitory synapses in the hippocampus. J Neurosci 35:11252-11265. CrossRef Medline

Teyler TJ, Vardaris RM, Lewis D, Rawitch AB (1980) Gonadal steroids: effects on excitability of hippocampal pyramidal cells. Science 209:10171018. CrossRef Medline

Waters EM, Thompson LI, Patel P, Gonzales AD, Ye HZ, Filardo EJ, Clegg DJ, Gorecka J, Akama KT, McEwen BS, Milner TA (2015) G-proteincoupled estrogen receptor 1 is anatomically positioned to modulate synaptic plasticity in the mouse hippocampus. J Neurosci 35:2384-2397. CrossRef Medline

Wong M, Moss RL (1992) Long-term and short-term electrophysiological effects of estrogen on the synaptic properties of hippocampal CA1 neurons. J Neurosci 12:3217-3225. Medline

Zadran S, Qin Q, Bi X, Zadran H, Kim Y, Foy MR, Thompson R, Baudry M (2009) 17-Beta-estradiol increases neuronal excitability through MAP kinase-induced calpain activation. Proc Natl Acad Sci U S A 106:2193621941. CrossRef Medline

Zhao L, Woody SK, Chhibber A (2015) Estrogen receptor beta in Alzheimer's disease: from mechanisms to therapeutics. Ageing Res Rev 24:178 190. CrossRef Medline 